\title{
Analysis of Doppler Lidar Data Acquired during the Pentagon Shield Field Campaign
}

RK Newsom

April 2011

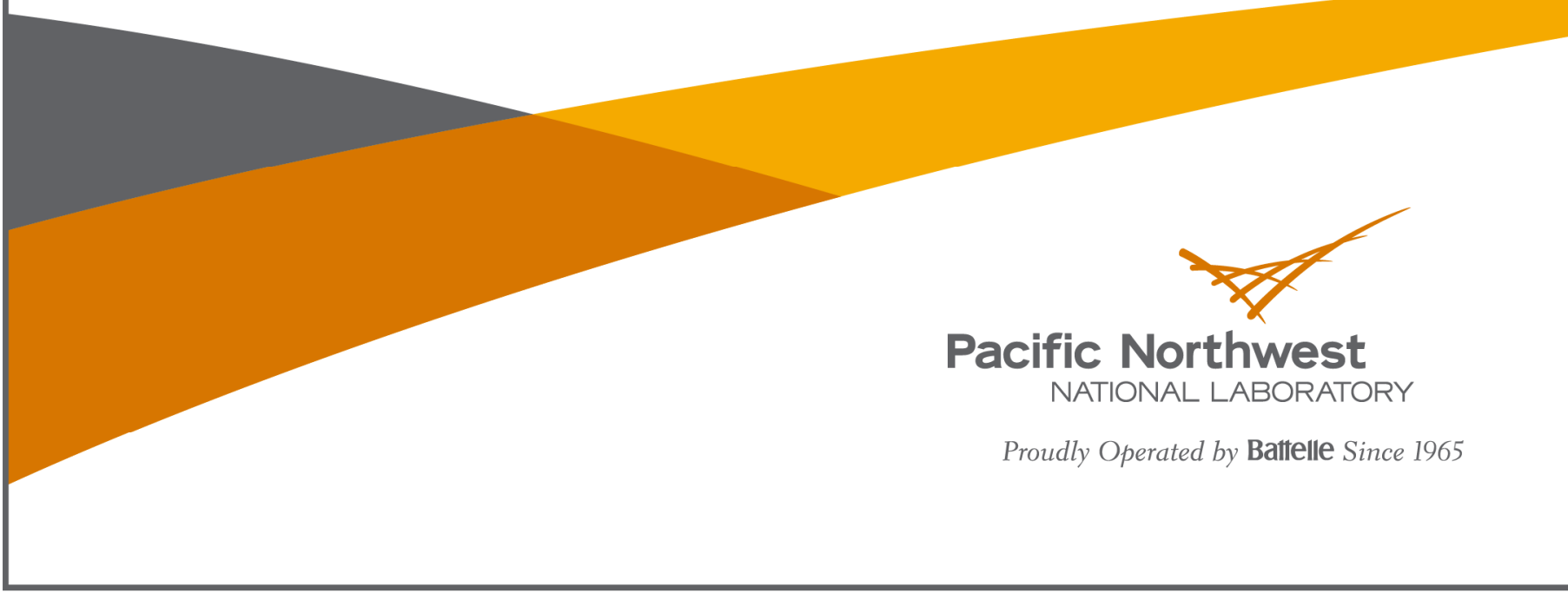




\title{
DISCLAIMER
}

This report was prepared as an account of work sponsored by an agency of the United States Government. Neither the United States Government nor any agency thereof, nor Battelle Memorial Institute, nor any of their employees, makes any warranty, express or implied, or assumes any legal liability or responsibility for the accuracy, completeness, or usefulness of any information, apparatus, product, or process disclosed, or represents that its use would not infringe privately owned rights. Reference herein to any specific commercial product, process, or service by trade name, trademark, manufacturer, or otherwise does not necessarily constitute or imply its endorsement, recommendation, or favoring by the United States Government or any agency thereof, or Battelle Memorial Institute. The views and opinions of authors expressed herein do not necessarily state or reflect those of the United States Government or any agency thereof.

\author{
PACIFIC NORTHWEST NATIONAL LABORATORY \\ operated by \\ BATTELLE \\ for the \\ UNITED STATES DEPARTMENT OF ENERGY \\ under Contract DE-AC05-76RL01830
}

Printed in the United States of America
Available to DOE and DOE contractors from the Office of Scientific and Technical Information,
P.O. Box 62, Oak Ridge, TN 37831-0062;
ph: (865) 576-8401
fax: $(865)$ 576-5728
email: reports@adonis.osti.gov

\begin{abstract}
Available to the public from the National Technical Information Service, U.S. Department of Commerce, 5285 Port Royal Rd., Springfield, VA 22161 ph: (800) 553-6847 fax: $(703) 605-6900$ email: orders@ntis.fedworld.gov online ordering: http://www.ntis.gov/ordering.htm
\end{abstract}

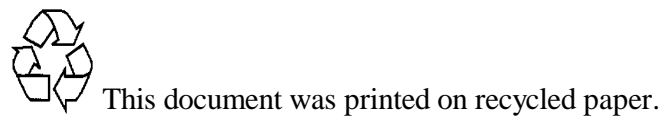




\section{Analysis of Doppler Lidar Data Acquired during the Pentagon Shield Field Campaign}

RK Newsom

April 2011

Prepared for

the U.S. Department of Energy

under Contract DE-AC05-76RL01830

Pacific Northwest National Laboratory

Richland, Washington 99352 



\section{Abstract}

Observations from two coherent Doppler lidars deployed during the Pentagon Shield field campaign are analyzed in conjunction with other sensors to characterize the overall boundary-layer structure, and identify the dominant flow characteristics during the entire two-week field campaign. Convective boundary layer (CBL) heights and cloud base heights (CBH) are estimated from an analysis of the lidar signal-to-noise-ratio (SNR), and mean wind profiles are computed using a modified velocity-azimuthdisplay (VAD) algorithm. Three-dimensional wind field retrievals are computed from coordinated overlapping volume scans, and the results are analyzed by visualizing the flow in horizontal and vertical cross sections.

The VAD winds showed that southerly flows dominated during the two-week field campaign. Lowlevel jets (LLJ) were evident on all but two of the nights during the field campaign. The LLJs tended to form approximately two hours after sunset and reached maximum strength between 03 and 07 UTC. The surface friction velocities show distinct local maxima during four nights when strong LLJs formed.

Estimates of the convective boundary layer height and residual layer height are obtained through an analysis of the vertical gradient of the lidar SNR. Strong minimum in the SNR gradient often develops just above the surface after sunrise. This minimum is associated with the developing Convective Boundary Layer (CBL), and increases rapidly during the early portion of the daytime period. On several days, this minimum continued to increase until around sunset. Secondary minima in the SNR gradient were also observed at higher altitudes, and are believed to be remnants of the CBL height from previous days (i.e., the residual layer height).

The dual-Doppler analysis technique used in this study makes use of hourly averaged radial velocity data to produce three-dimensional grids of the horizontal velocity components, and the horizontal velocity variance. Visualization of horizontal and vertical cross sections of the dual-Doppler wind retrievals often indicated a jet-like flow feature over the Potomac River under southerly flow conditions. This linear flow feature is roughly aligned with the Potomac River corridor to the south of the confluence with the Anatostia River, and is most apparent at low levels (i.e., below $150 \mathrm{~m} \mathrm{MSL}$ ). It is believed that this flow occurs due to reduced drag over the water surface and when the large scale flow aligns with the Potomac River corridor.

An area-constrained VAD analysis generally confirmed the observations from the dual-Doppler analysis. When the large-scale flow is southerly, wind speeds over the Potomac River are consistently larger than at a site just to the west of the river for altitudes less than $100 \mathrm{~m} \mathrm{MSL}$. Above this level, the trend is somewhat less obvious. The data suggests that the depth of the wind speed maximum may be reduced by strong directional shear aloft. 



\section{Acronyms and Abbreviations}

$\mathrm{CBH} \quad$ Cloud Base Height

CBL Convective Boundary Layer

IOP Intensive Operation Period

LLJ Low Level Jet

MSL Mean Sea Level

PBL Planetary Boundary Layer

PM Pulse Monitor

UTC Universal Coordinated Time

VAD A $360^{\circ}$ Plan Position Indicator scan 



\section{Contents}

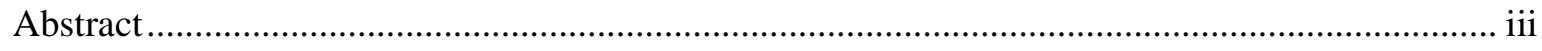

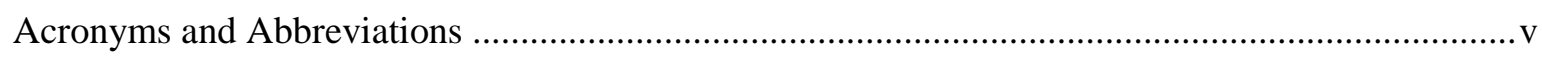

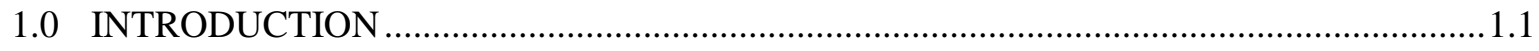

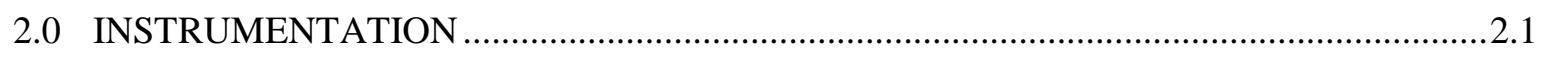

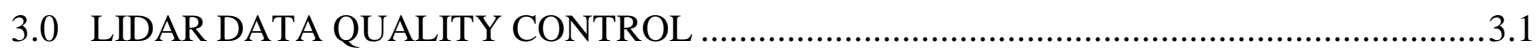

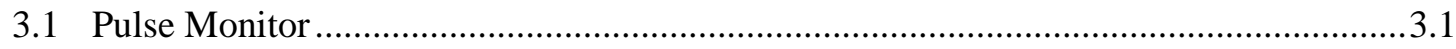

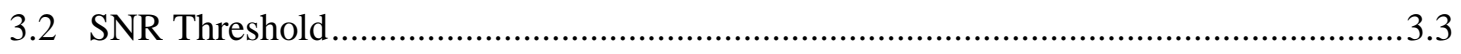

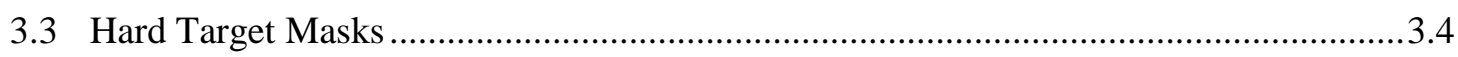

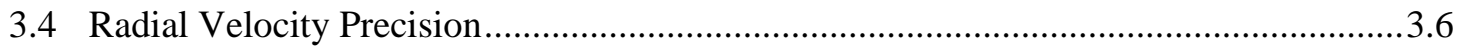

4.0 BOUNDARY LAYER CHARACTERIZATION ......................................................... 4.1

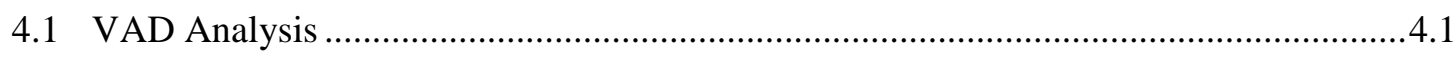

4.2 PBL Height Estimates, CBH, and Surface Fluxes ......................................................... 4.3

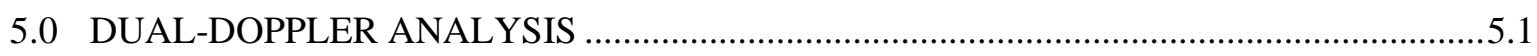

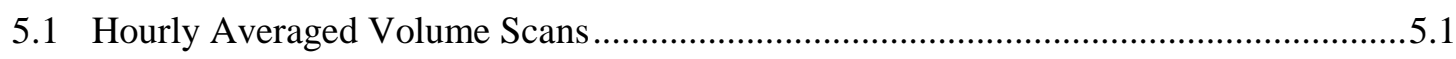

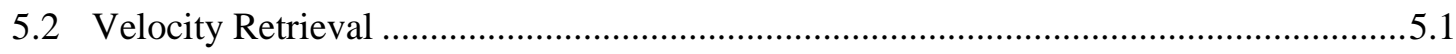

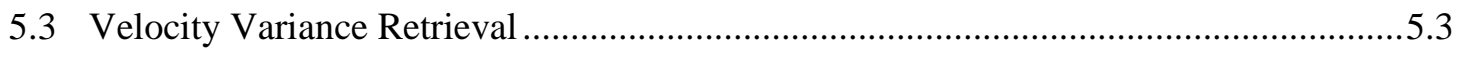

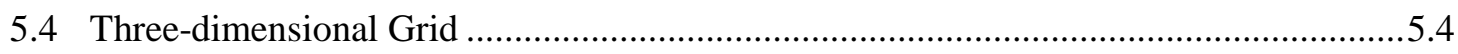

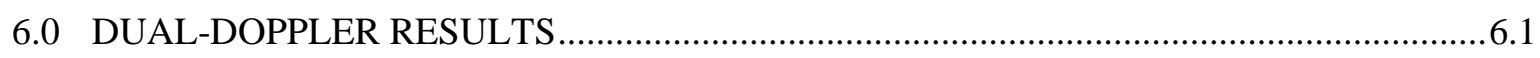

7.0 VALIDATION OF THE DUAL-DOPPLER RETRIEVALS ............................................... 7.1

7.1 Comparion between Radial Velocity Scans ............................................................... 7.1

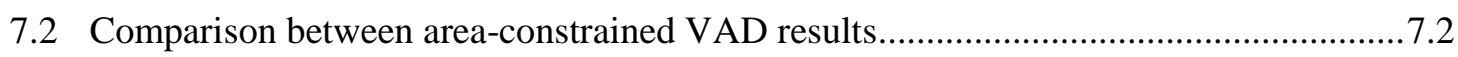

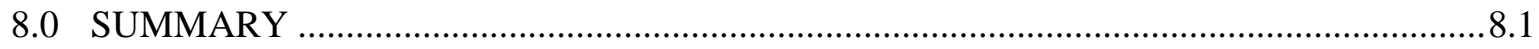




\section{Figures}

Figure 1. Deployment locations of the Annex and Bolling lidars during the Pentagon Shield field campaign

Figure 2. Specifications of the Lockheed Martin WindTracer® Doppler lidar.

Figure 3. Energy monitor signals for (a) the Bolling lidar and (b) the Annex lidar for 5 May 2004.

Figure 4. Time-height cross sections of (a) Radial velocity and (b) SNR from the Bolling Lidar between 1343:10 to 1348:00 UTC on 5 May 2004....

Figure 5. (a) Time-height cross section of the unfiltered radial velocity field. (b) Time-series of the PM signal.

Figure 6. Time series of data availability for (a) the Bolling and (b) the Annex lidars during 5 May 2004.

Figure 7. Representative examples of radial velocity data from the Bolling lidar after pulse monitor and SNR thresholding.

Figure 8. Development and application of a static hard target mask......

Figure 9. Nearly simultaneous scans show radial velocity from the (a) Bolling lidar, and (b) the Annex lidar.

Figure 10. Radial velocity measurement error as a function of SNR for the (a) Annex and (b) Bolling lidars

Figure 11. Time-height cross sections of the mean horizontal winds computed from (a) the Annex lidar data, and (b) the Bolling lidar data using the modified.

Figure 12. This is the same as Figure 11 except that the time period shown is from 7-13 May 2004.

Figure 13. Boundary layer structure as observed by Annex lidar and surface flux station at the National Arboretum for the period from 1-7 May 2004.

Figure 14. This is the same as Figure 13 except the period covers 7-13 May 2004.........

Figure 15. Schematic illustration of the dual-Doppler analysis method.

Figure 16. Vertical cross section of dual-Doppler derived (a) wind speed, (b) wind direction deviation, and (c) velocity variance at 20:00 UTC on 1 May 2004.

Figure 17. This is the same as Figure 16, except 19:00 UTC on 2 May 2004.

6.3

Figure 19. This is the same as Figure 16, except 17:00 UTC on 8 May 2004

6.4

Figure 20. This is the same as Figure 16, except 20:30 UTC on 10 May 2004.

Figure 21. Panels (b) through (f) show horizontal cross-sections of wind speed from the dualDoppler analysis for 2000 UTC on 12 May 2004.

Figure 22. This is the same as Figure 21 except the time period is 2000 UTC on 12 May 2004.

Figure 23. This is the same as Figure 21 except the time period is 1400 UTC on 2 May 2004.

Figure 24. Large-scale map of the field study site. The long arrow indicates the relatively long fetch over water available to southerly flows.

Figure 25. Comparison between hourly averaged radial velocity scans from (a) the Annex lidar, and (b) the Bolling lidar for 2030 UTC on 2 May 2004.

Figure 26. Horizontal coverage of the area-constrained VADs for the Annex and Bolling lidars. 
Figure 27. (a) Absolute and (b) Relative wind speed differences between the Bolling and Annex lidars for the period from 1-7 May 2004..

Figure 28. This is the same as Figure 27 except the period is for 7-13 May 2004.

\section{Tables}

Table 1. Start and end times for the periods containing valid dual-Doppler retrievals.............

6.1 



\subsection{INTRODUCTION}

The Pentagon Shield field campaign was conducted in the Washington DC area during the first two weeks of May 2004 (Warner 2007). The primary goal of this field campaign was to improve the understanding of micro-scale pollutant transport and dispersion in a complex urban environment, with an emphasis on dispersion in and around the Pentagon. A large number of instruments were deployed as part of the field campaign including two Doppler lidars. This study focuses specifically on the analysis of data acquired by the Doppler lidars.

The lidars were deployed and operated to enable dual-Doppler post-processing of the data (Collier 2005). These systems were configured to perform repeated volume scans throughout the two-week field campaign. The focus of the current study is to use the data from the lidars, in conjunction with other sensors to:

1) Characterize the overall boundary-layer structure

2) Generate highly resolved wind retrievals from the dual-Doppler lidar scans

3) Analyze the results of the dual-Doppler retrieval in order to understand the dominate flow characteristics over the study area during the field campaign.

There were a total of five Intensive Operation Periods (IOP) conducted throughout the two-week Pentagon Shield field campaign. These IOPs typically started a few hours before sunset and continued into the early morning hours. Unfortunately, one of the lidars, the Army Research Laboratory system, experienced frequent periods of degraded performance, particularly at night. This system often did not function well during IOPs. There were, however, many hours of valid measurements from the Army Research Laboratory lidar during non-IOP periods. In order to exploit as much valid data as possible, this study examined data from the entire two-week field deployment, without regard to specific IOPs.

In Section 2 we describe the instrumentation, deployment locations, and scan strategies. Section 3 describes lidar data quality control procedures, including pulse monitor and SNR thresholds, filtering to identify and reject hard target returns, and Doppler velocity measurement precision estimation. In Section 4, lidar data and surface flux measurements are used to characterize the boundary layer during the entire two-week field campaign. This includes an analysis of the attenuate backscatter fields to determine boundary layer heights, cloud base heights, and VAD analysis of the Doppler velocities. Section 5 describes the techniques that were used to process the dual-Doppler lidar observations, and Section 6 presents the results of the dual-Doppler analysis. Studies to validate the dual-Doppler wind retrievals are presented in Section 7. This includes a comparison of so-called area-constrained VAD winds between the Bolling and Annex lidars. Finally, Section 8 summarizes the results of the entire study. 



\subsection{INSTRUMENTATION}

Figure 1 shows deployment locations for the Annex and Bolling lidars during the Pentagon Shield field campaign. The Annex lidar was deployed atop the Navy Annex building, approximately $500 \mathrm{~m}$ west of the Pentagon. A second lidar, operated by the Army Research Laboratory, was deployed approximately $5 \mathrm{~km}$ to the southeast of the Annex lidar, next to the Potomac River at Bolling Air Force Base. The Annex and Bolling lidars are both coherent WindTracer ${ }^{\circledR}$ Doppler lidars that operate at a wavelength of $2 \mu \mathrm{m}$ (Henderson et al. 1991, 1993). The WindTracer® is manufactured by Lockheed Martin. Figure 2 describes the performance characteristics of the Lockheed Martin WindTracer@.

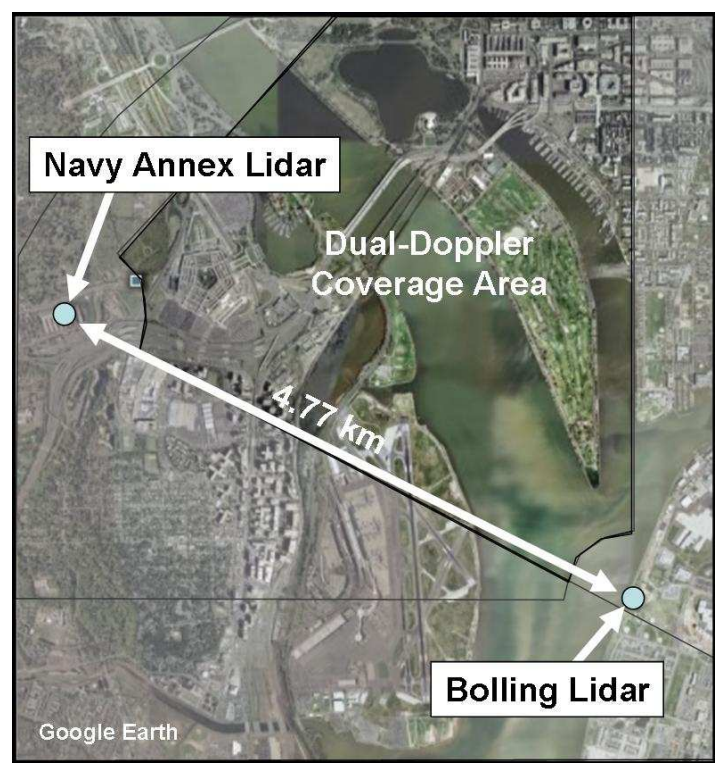

Figure 1. Deployment locations of the Annex and Bolling lidars during the Pentagon Shield field campaign. The Annex lidar scanned toward the east and the Bolling lidar scanned toward the northwest. The region of overlap between the two scans is indicated. The overlap region includes the Pentagon, the Potomac River, East Potomac Park, and portions of the National Mall area.

\begin{tabular}{|ll|}
\hline Manufacturer: & Lockheed Martin Coherent Technologies \\
Maximum Range: & $8-10 \mathrm{~km}$ \\
Minimum Range: & $\sim 400 \mathrm{~m}$ \\
Velocity Range: & $\pm 20 \mathrm{~m} \mathrm{~s}^{-1}$ \\
Velocity Accuracy: & $0.1-0.6 \mathrm{~m} \mathrm{~s}^{-1}$ RMS @ high SNR (SNRN > 5-10 dB) \\
Range Resolution: & $80-100 \mathrm{~m}^{\prime}$ typical \\
Transmitter Wavelength: & $2 \mu \mathrm{m}$ \\
Pulse Energy: & $2 \mathrm{~mJ} \pm 0.5 \mathrm{~mJ}$ \\
Pulse Duration: & $\sim 400 \mathrm{~ns}(\sim 60 \mathrm{~m})$ \\
Pulse Repetition Frequency: & $500 \mathrm{~Hz}$ \\
Aperature Diameter: & $10 \mathrm{~cm}$ \\
Beam Diameter: & $8 \mathrm{~cm}$ \\
\hline \hline Source: http://mmw.lockheedmartin.com
\end{tabular}

Figure 2. Specifications of the Lockheed Martin WindTracer® Doppler lidar.

During the two week deployment both lidars performed overlapping volume scans and were operated almost continuously. The same scan schedules for both lidars were maintained throughout the duration of the deployment. The Bolling lidar performed volume scans over the northwest sector, as indicated in Figure 1. The volume scans were performed at 10 elevation angles $\left(0.9^{\circ}, 1.8^{\mathrm{o}}, 2.7^{\mathrm{o}}, 3.6^{\mathrm{o}}, 4.5^{\mathrm{o}}\right.$, $5.4^{\circ}, 6.3^{\circ}, 7.2^{\circ}, 8.1^{\circ}$, and $9.0^{\circ}$ ). There was one slight modification to the scan schedule during the 
deployment. From 1-4 May 2004 the azimuth limits of the volume scans were set to $258^{\circ}$ and $348^{\circ}$. After 4 May this was changed to $270^{\circ}$ and $360^{\circ}$. A complete $360^{\circ}$ plan position indicator scan, or VAD scan was performed at an elevation angle of $24^{\circ}$ following each volume scan.

The Annex lidar performed volume scans over a $90^{\circ}$ sector toward the east, as indicated in Figure 1. The volume scans were performed at 10 elevation angles, $-1.0,1.5,4.0,6.5,9.0,11.5,14.0,16.5,19.0$, 21.5 , between azimuth angles of $32^{\circ}$ and $122^{\circ}$. Moreover, a complete $360^{\circ}$ PPI, or VAD scan was performed at an elevation angle of $24^{\circ}$ following each volume scan. This same scan schedule was maintained for the duration of the two-week field campaign. The time to complete each volume and VAD scan combination was approximately 5 minutes for both the Annex and Bolling lidars.

For consistency, both lidar systems were operated with the same signal processing parameters throughout the field campaign. The number of shots averaged was 50, resulting in a beam rate of $10 \mathrm{~Hz}$. At a Pulse Repetition Frequency (PRF) of $500 \mathrm{~Hz}$, this resulted in one beam every 0.1 seconds. The gate size and the spacing between gate centers were both set to $72 \mathrm{~m}$. The range to the center of the first gate was $636 \mathrm{~m}$.

This study also made use of other instruments in addition to the lidars including flux measurements from DCnet (http://dcnet.atdd.noaa.gov/) and data from radiosondes. 


\subsection{LIDAR DATA QUALITY CONTROL}

Data quality control involved filtering out radial velocity data corresponding to abnormally low laser pulse energies, low SNR, and fixed hard target returns. Additionally, estimates of the measurement precision, as a function of SNR, were obtained through analysis of radial velocity signals. The measurement precision was used to estimate errors associated with the VAD and dual-Doppler wind retrievals.

\subsection{Pulse Monitor}

For a coherent system, the pulse monitor (PM) signal is a measure of the power of the outgoing laser pulse prior to propagation through the atmosphere. It is formed by diverting a small fraction of the outgoing pulse, mixing it with the local oscillator, and measuring the coherent power in exactly the same way that the atmospheric return is measured. The pulse monitor signal represents the peak value of the Doppler spectrum. Alternately, the SNR is a ratio of the coherent energy of the atmospheric return to the total energy contained in the noise floor over the pass-band of the Doppler spectrum.

Data quality control involved filtering out radial velocity data corresponding to abnormally low laser pulse energies, low SNR, and fixed hard target returns. Additionally, estimates of the measurement precision, as a function of SNR, were obtained through analysis of radial velocity signals. The measurement precision was used to estimate errors associated with the VAD and dual-Doppler wind retrievals.

Figure 3 shows PM signals for the Annex and Bolling lidars for one representative diurnal cycle (5 May 2004). Figure 3a indicates that the PM signal for the Bolling lidar decreases rapidly after sunset (approximately 0000 UTC), and remains very low throughout the nighttime period. About 3 hours after sunrise (approximately 1000 UTC) the PM signal begins to increase, but experiences significant fluctuation during the day. By contrast, the PM signal for the Annex lidar (Figure 3b) is significantly higher, and more stable throughout the entire diurnal cycle.

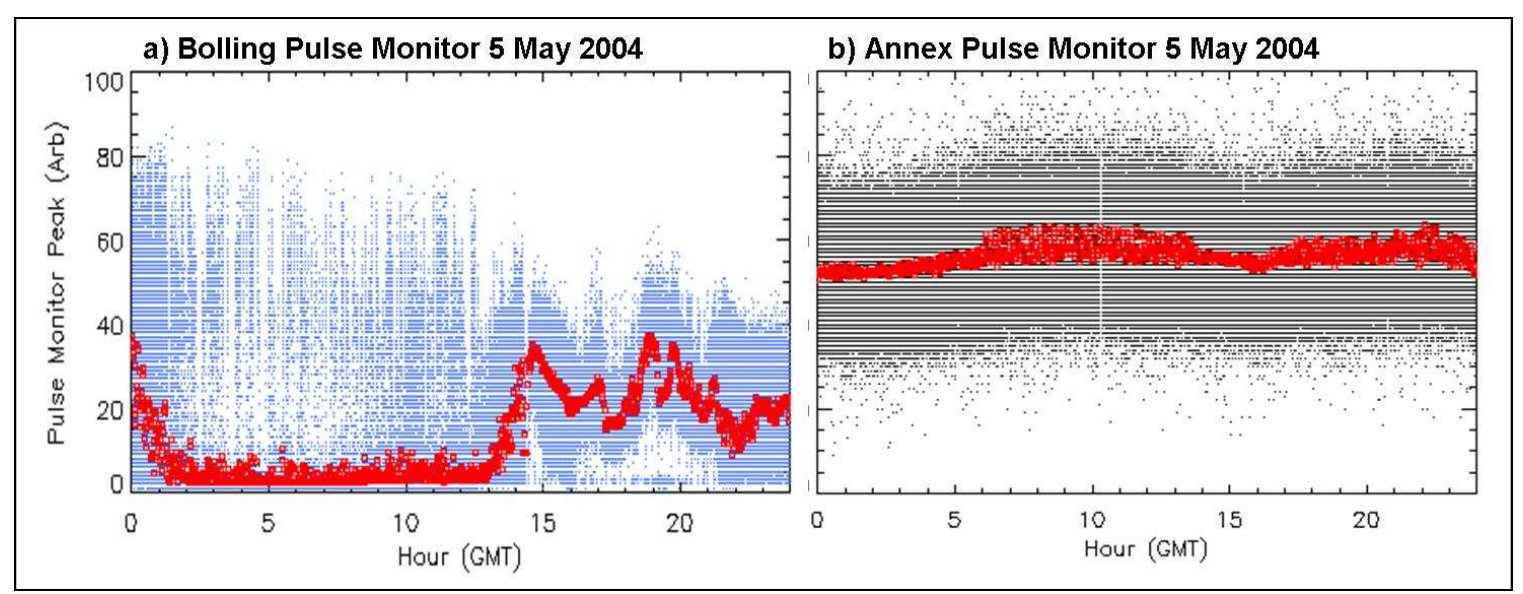

Figure 3. Energy monitor signals for (a) the Bolling lidar and (b) the Annex lidar for 5 May 2004. Blue (Bolling) and black (Annex) points represent pulse monitor values for each beam. The red points are averages of the pulse monitor signal over one scan file (approximately 5 minutes). 
Figure 4 shows the Phase Modulation (PM) signal, radial velocity and SNR for the Bolling lidar during a period of degraded performance. When the PM signal is small (roughly $<10$ ) the radial velocity data is clearly corrupted, and the SNR does not show its characteristic fall-off with range. This suggests that a simple filtering method based on a minimum PM value may be effective at removing much of this poor quality data.

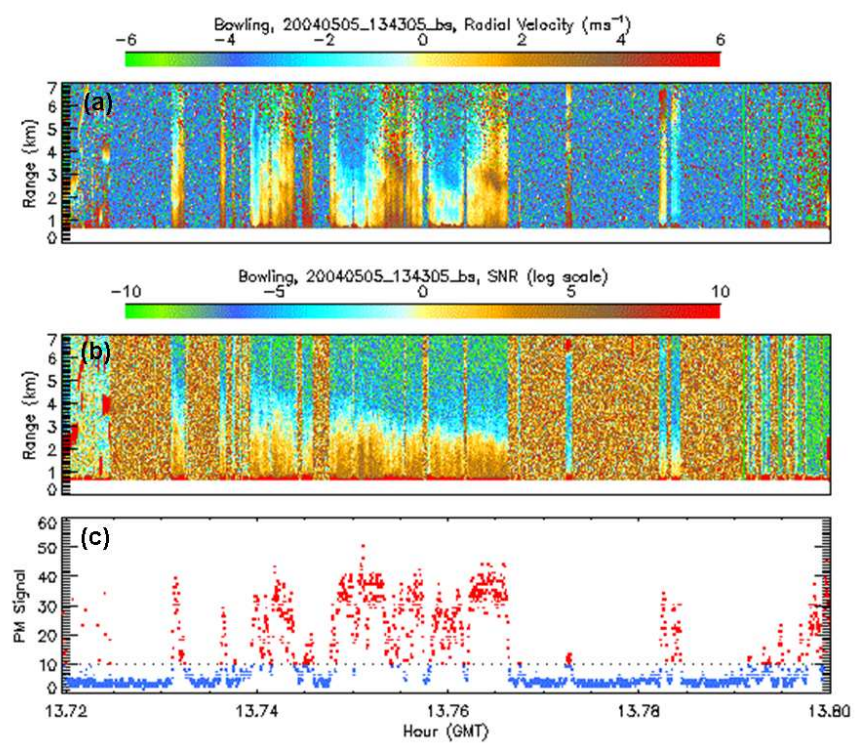

Figure 4. Time-height cross sections of (a) Radial velocity and (b) SNR from the Bolling Lidar between 1343:10 to 1348:00 UTC on 5 May 2004. The bottom panel shows the corresponding time series of the pulse monitor signal. Pulse monitor data above 10 are shown in red, and values below 10 are shown in blue.

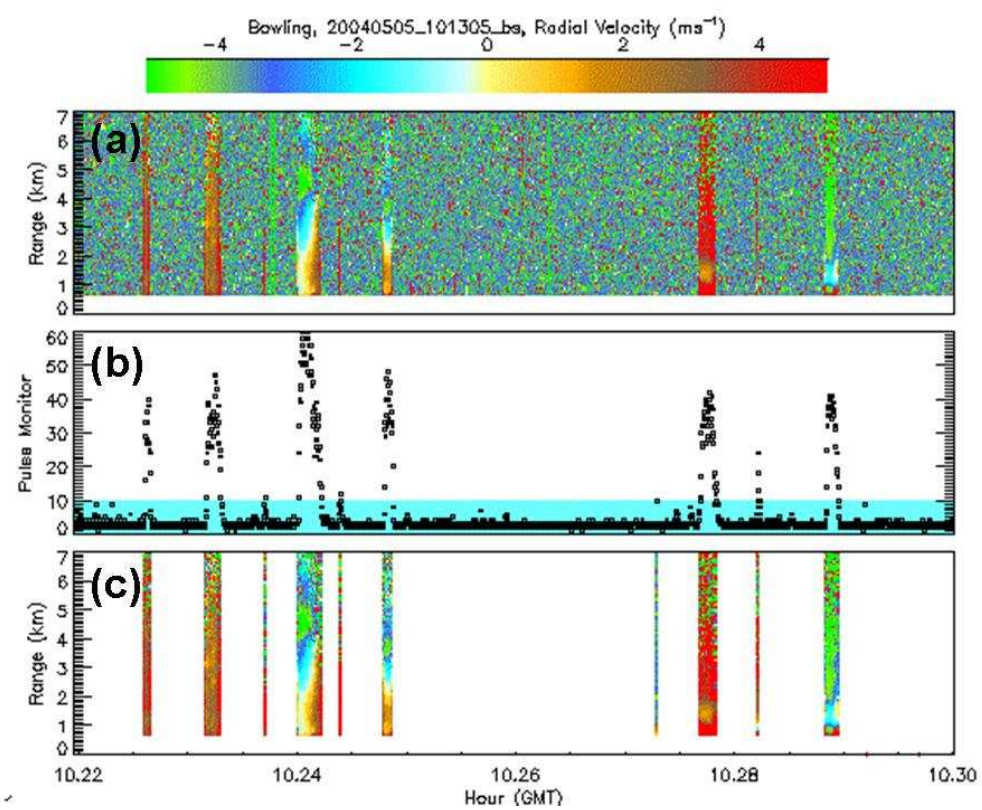

Figure 5. (a) Time-height cross section of the unfiltered radial velocity field. (b) Time-series of the PM signal. The blue region highlights values below a prescribed threshold of 10. (c) Time-height cross section of the filtered radial velocity field. 
Part of data quality control procedure involved filtering out radial velocity profiles corresponding to PM values below 10. Figure 5 illustrates the effect this had on the radial velocity data from the Bolling lidar. Although this technique appears to be effective at removing poor quality data, it can create many data voids. This presents challenges for the VAD and dual-Doppler wind retrieval algorithms.

Figure 6 shows a representative time series of the availability of data from the Annex and Bolling lidars during one representative diurnal cycle. The blue areas in Figure 6 represent the fraction of time that the systems were operating, and the red areas indicate the fraction of time that the systems operated above a PM threshold of 10 .

The lidar functioned more or less normally during the first two days of the deployment. Significant problems began on 3 May 2004. On that day the percentage of usable data decreased below $10 \%$ after about 4 UTC. The data quality remained poor until data acquisition was ceased shortly after 12 UTC. The lidar did not start acquiring data again until slightly after 18 UTC on the following day (4 May 2004). At that time the lidar functioned well until sometime after 0 UTC on 5 May 2004. The data then deteriorated once again, and shortly after 1 UTC the percentage of usable data decreased below $10 \%$. The data improved again about 12 hours later and remained good for the duration of that day. Examination of the other days show similar trends. As indicated in Figure 6, the Annex lidar tended to perform quite well overall, while the Bolling lidar did well during the day, but experienced problems at night. Overall, the Bolling lidar performed best during afternoon periods, and poorest during early morning periods. Data availability plots for all days during the field campaign are presented in Appendix B.

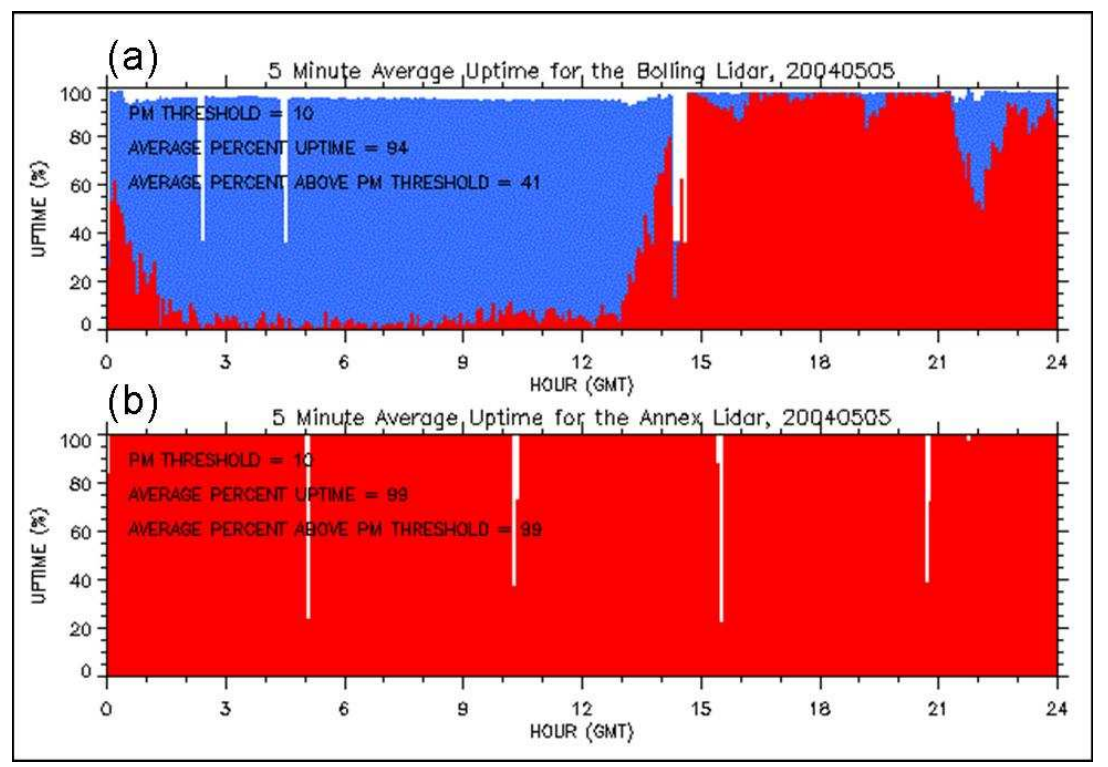

Figure 6. Time series of data availability for (a) the Bolling and (b) the Annex lidars during 5 May 2004. Blue indicates periods when the lidar was operating, while the red indicates the fraction of time that the pulse monitor signal exceeded 10. Data availability plots for all days of the Pentagon Sheild field campaign are presented in Appendix X.

\subsection{SNR Threshold}

In addition to PM thresholding, the quality control process involved rejection of radial velocity data corresponding to low SNR. At low SNR, radial velocity measurements become uniformly randomly 
distributed across the pass band of the receiver (Frehlich et al 1997; Rye and Hardesty 1993, 1997). As a result, the mean Doppler velocity goes to zero as the SNR goes to zero (because the pass band is symmetrical at about zero). Large biases can result in the VAD and dual-Doppler analyses if low SNR data was not properly filtered out. We used an SNR threshold of $-2 \mathrm{~dB}$ for this study. Figure 7 illustrates the effects of both PM and SNR thresholding on data from the Bolling lidar. The examples in this figure show representative scans of radial velocity during an afternoon period, when the lidar functioned well, and during a period shortly after sunset, when the lidar's performance was rapidly deteriorating.

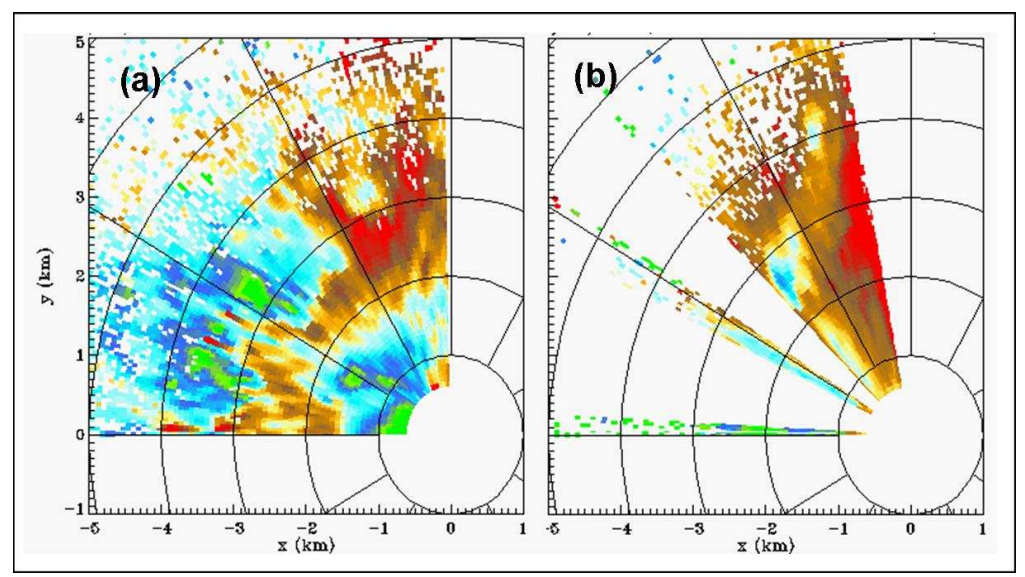

Figure 7. Representative examples of radial velocity data from the Bolling lidar after pulse monitor and SNR thresholding. Panel (a) shows typical data during an afternoon period, and panel (b) shows typical data several hours after sunset.

\subsection{Hard Target Masks}

Radial velocity data from stationary hard target returns cause biases in the dual-Doppler analysis. These features contaminate radial velocity measurements in the lowest elevation angles of the volume scans. Examples of stationary hard targets include terrain features, buildings, trees, etc. For this study, hard target returns were filtered out through the application of a masking process. The hard target masks were developed from SNR measurements averaged over several scans. For a given elevation angle the range corresponding to the maximum gradient in the SNR field was determined as a function of azimuth angle. This range then determined the transition between the masked and unmasked portions of the data, as illustrated in Figure 8. 

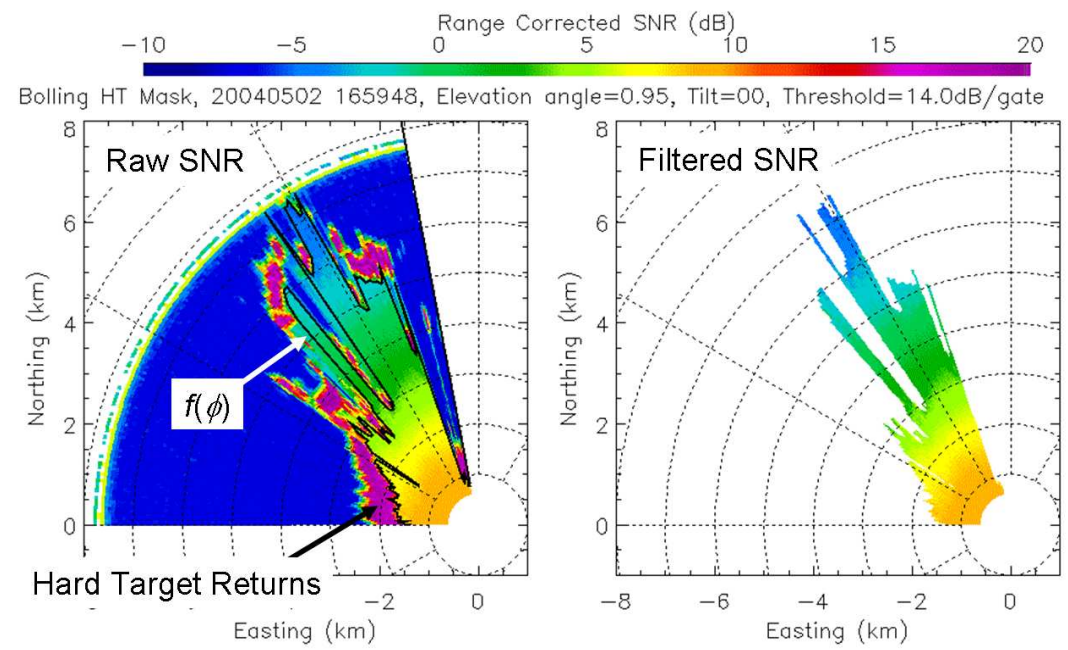

Figure 8. Development and application of a static hard target mask. The left panel shows the raw SNR field for the Bolling lidar at the lowest elevation angle of the volume scan $\left(0.95^{\circ}\right.$, tilt \#0). The solid black line shows the function $f(\phi)$, which gives the range, $r$, of the transition between the masked and unmasked portions of the data, as determined from the gradient of the (range corrected) SNR. The right panel shows the (range corrected) SNR field after the application of the hard target mask.

Figure 9 presents an example of radial velocity data that has been subjected to a hard target mask, and PM and SNR thresholding. This example shows nearly simultaneous scans from the Annex and Bolling lidar at approximately 1847 UTC on 1 May 2004. In this case, the hard target mask blocked measurements contaminated by ground returns in the Bolling lidar data just to the west of ReaganNational Airport.

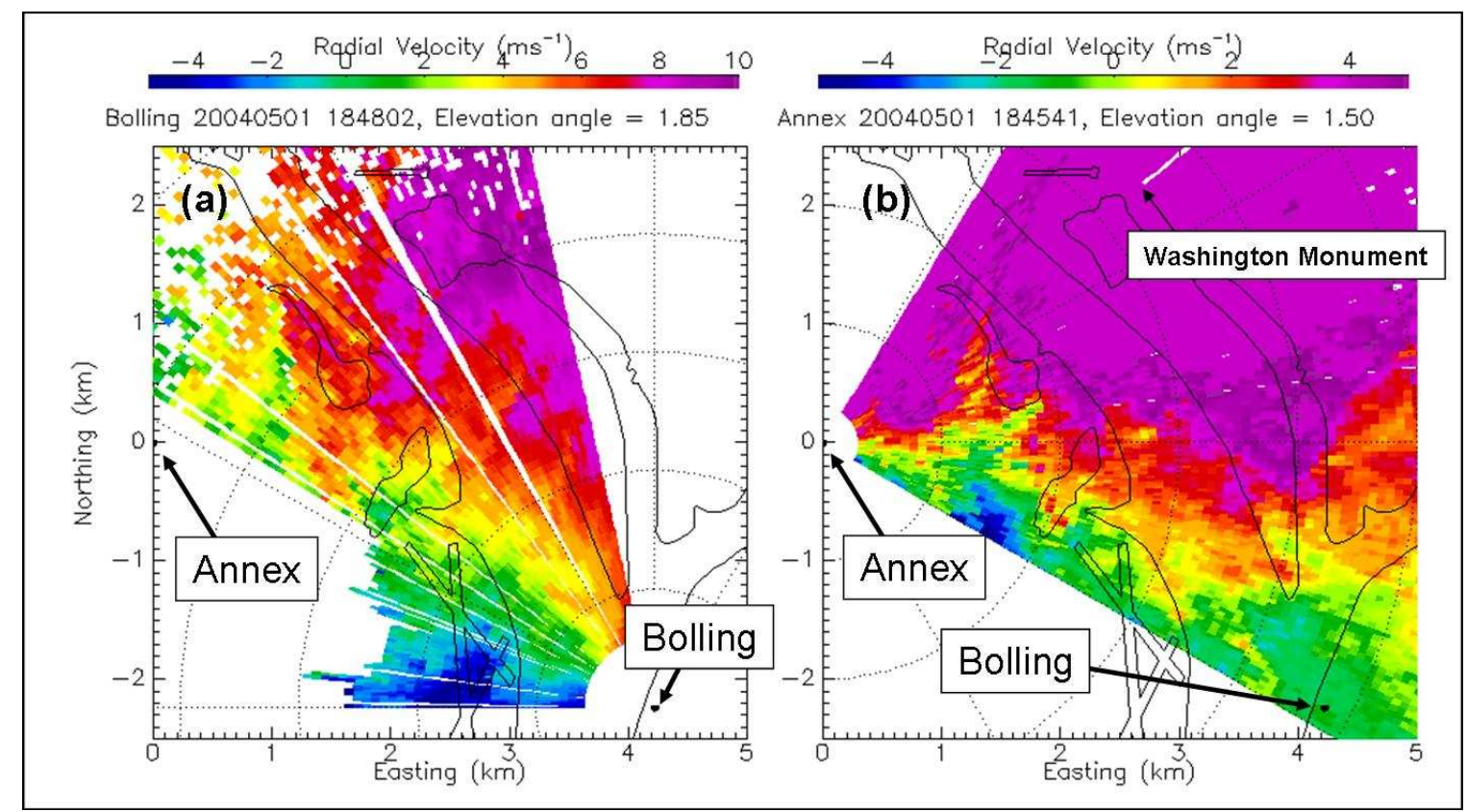

Figure 9. Nearly simultaneous scans show radial velocity from the (a) Bolling lidar, and (b) the Annex lidar. This data has been subjected to pulse monitor and SNR thresholding, and hard target masking. A local coordinate system is defined with the Annex lidar at the origin. Also shown are outlines indicating the Potomac River, Tidal Basins, and Reagan-National Airport. 


\subsection{Radial Velocity Precision}

Estimates of radial velocity measurement error were made in order to determine the atmospheric contribution to velocity variance (Lenschow et al. 2000; Lothon et al. 2006). The measurement precision was also used to estimate errors associated with the VAD and dual-Doppler wind retrievals. The basic idea is to develop an empirical relationship between SNR and velocity precision, and to use that relationship to assign a precision or error to all measurements in the dataset. The process of determining the precision as a function of SNR is typically done using staring data, where the random noise variance is estimated from the autocovariance of the radial velocity time series (Pearson et al. 2009; Frehlich 2001; Frehlich 2004). No staring data was available for current dataset. Instead, data from individual VAD scans were used to compute autocovariance functions. This was not ideal since the sample sizes were fairly small (most VAD scans contained less than 500 individual beams). However, hundreds of VAD scans were performed over the course of the two-week deployment. Thus, a reasonable estimate of velocity precision versus SNR could be obtained for each lidar by combining estimates from all the VAD scans. The results are shown in Figures 10.

As discussed in Section 3.2, an SNR threshold of -2dB is applied to the raw measurements. Figure 10 indicates that at this threshold level, measurements with velocity precisions larger than $\sim 1.0 \mathrm{~ms}^{-1}$ are rejected.
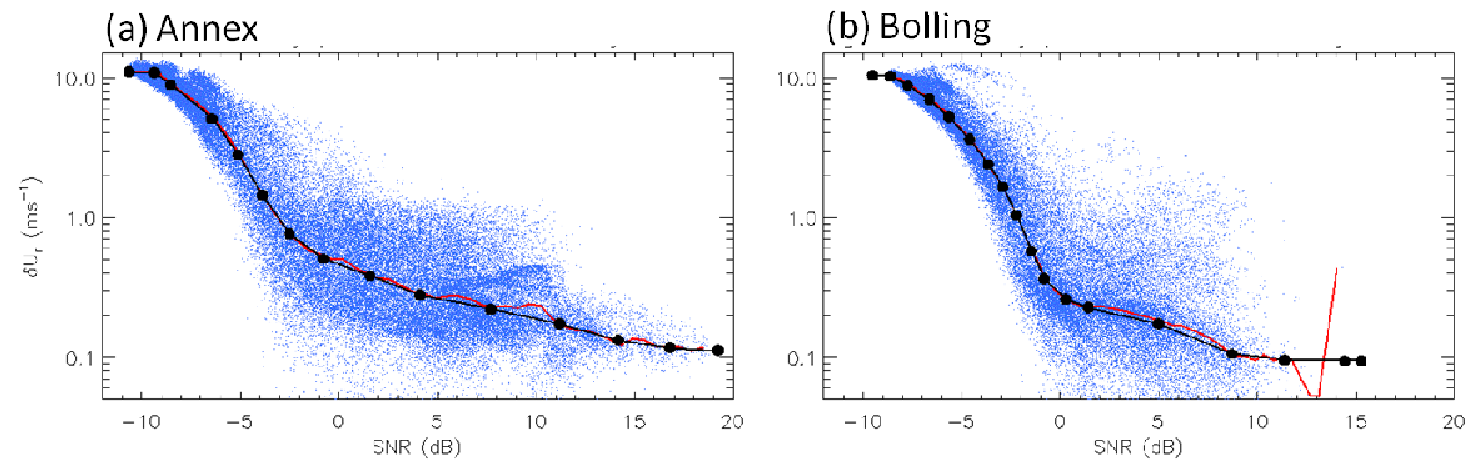

Figure 10. Radial velocity measurement error as a function of SNR for the (a) Annex and (b) Bolling lidars. The solid black line is the estimate of the (mean) velocity precision. The blue dots represent estimates obtained from individual VAD scans from 1-13 May 2004. 


\subsection{BOUNDARY LAYER CHARACTERIZATION}

In this section, observations from the Bolling and Annex lidars, as well as surface flux measurements are used to characterize the structure and stability of the Planetary Boundary Layer (PBL) during the Pentagon Shield field campaign.

\subsection{VAD Analysis}

A velocity-azimuth-display (VAD) analysis was conducted in order to develop estimates of the mean horizontal winds as a function of height over the course of the entire two-week field campaign. For this study we used a modified VAD analysis (Banta et al. 2002), as compared to the classic algorithm described by Browning and Wexler (1968).

In the modified VAD algorithm, all the radial velocity $u r$ data acquired during a given time period are divided into 60-m vertical bins, regardless of the type of scan the data came from. A given bin may contain $u r$ measurements scattered over a variety of azimuth and elevation angles, depending on the scans performed during that period. It is assumed that within a vertical bin the mean wind is horizontally homogeneous. The components of the mean horizontal winds $u$ and $v$ within a vertical bin are obtained by minimizing the total squared deviation between the radial component of the mean velocity, and the $u r$ measured by the lidar. This processing technique was applied to the entire Pentagon Shield dataset using a 30-minute averaging period oversampled at 15-minute intervals. The linear system that resulted from the least squares minimization had no solution if all of the azimuth angles were the same during the averaging period. The system will be ill-conditioned if the difference between the minimum and maximum azimuth is small. Mean wind estimates derived from ill-conditioned linear systems, as well as very noisy data, are excluded based on quality parameters that are proportional to the computed error in the retrieved mean velocity components. The quality parameters provide an objective method of rejecting bad estimates.

The results of the modified VAD analysis for the period from 1-7 May, and 7-13 May 2004 are shown in Figures 11 and 12, respectively. Overall, there is positive agreement between the results of the Annex and Bolling lidars. The results for the Bolling lidar are quite reasonable despite the problems with its transmit laser during the night. Although much of the nighttime data from the Bolling lidar was corrupted, the system was still able to produce some valid data intermittently during these periods.

Figures 11 and 12 generally indicate that under fair weather conditions a southerly flow tended to dominate, although there were several periods where weather disturbances modified this tendency. Periods of significant low-level cloudiness resulted in data voids aloft on the $2^{\text {nd }}, 3^{\text {rd }}, 5^{\text {th }}$, and $8^{\text {th }}$, whereas the loss in signal aloft on the $6^{\text {th }}$ appears to be due to exceptionally clean air. Low-level jet (LLJ) (Banta et al. 2002; Blackadar 1957; Bonner 1968; Mitchell et al.1995; Thorpe and Guymer 1977; Whiteman et al. 1997; Stensrud 1996) structures were also evident during most of the nighttime periods. In fact, the only nights that didn't clearly show LLJs were the $2^{\text {nd }}$ and the $6^{\text {th }}$. It is possible that cloudiness on the $2^{\text {nd }}$ and exceptionally clean air on the $6^{\text {th }}$ may have obscured the LLJ from the lidar. On nights when LLJ's are apparent, we observe that LLJs tend to form a couple of hours after sunset and reach their maximum strength between 03 and 07 UTC. For this location and this time of the year, sunrise occurs at about 10 UTC, and sunset occurs at about 00 UTC. 
(a) Annex Lidar

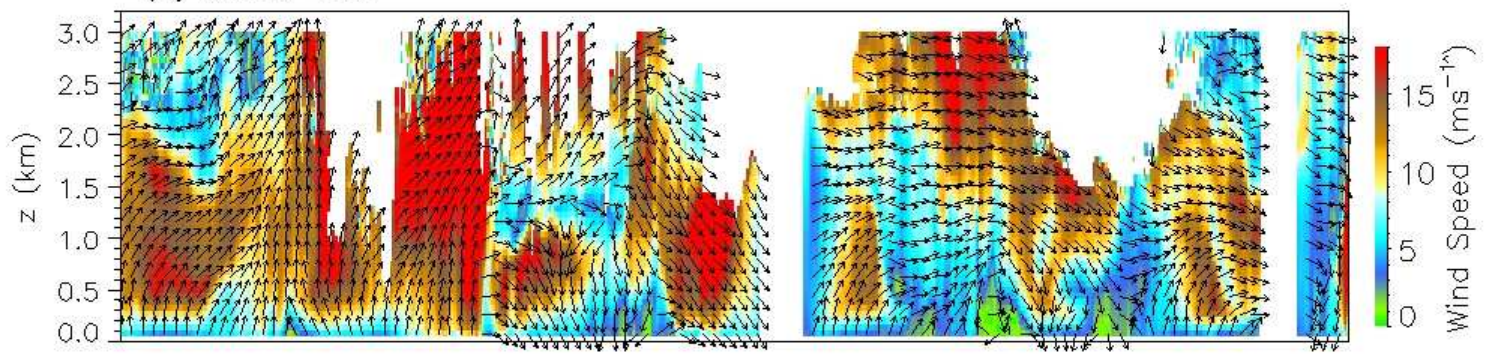

(b) Bolling Lidor

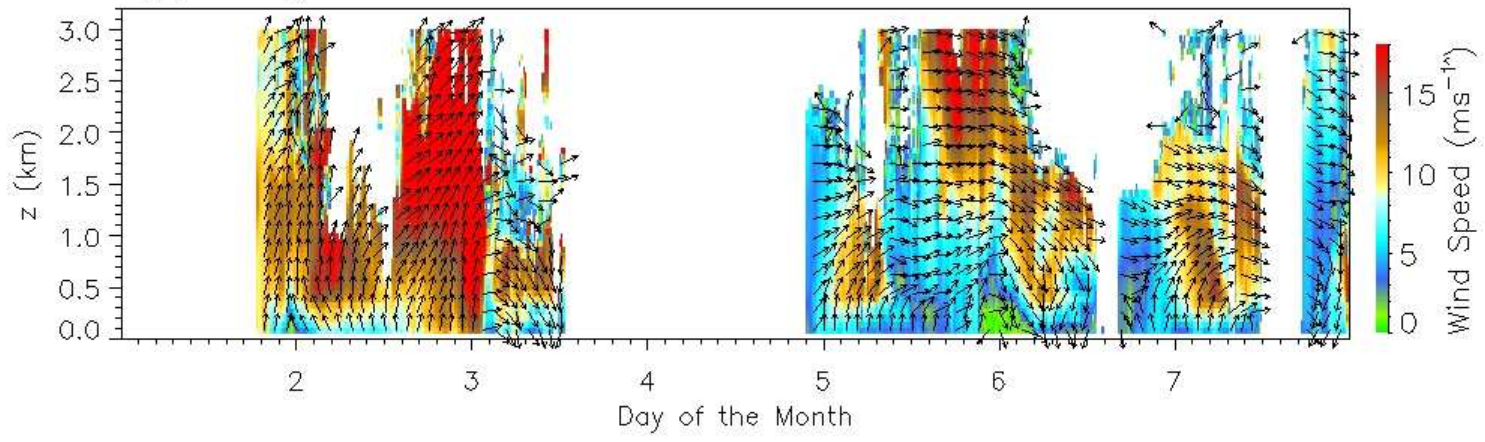

Figure 11. Time-height cross sections of the mean horizontal winds computed from (a) the Annex lidar data, and (b) the Bolling lidar data using the modified VAD analysis method. The time period shown is from 1-7 May 2004. Colors indicate wind speed, and the arrows indicate the flow direction in the horizontal direction (i.e., upward pointing arrows indicate a southerly flow, and right pointing arrows indicate a westerly flow).

(a) Annex Lidar

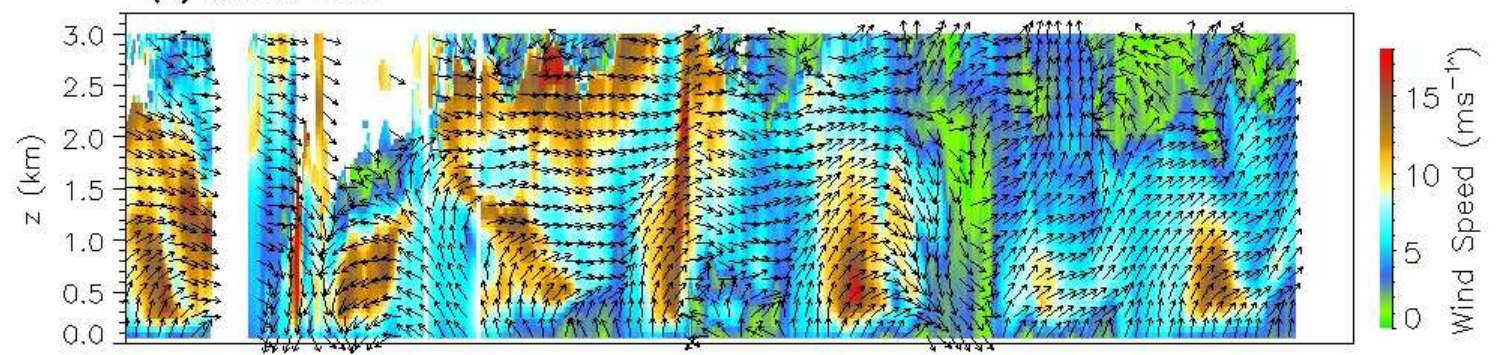

(b) Bolling Lidor

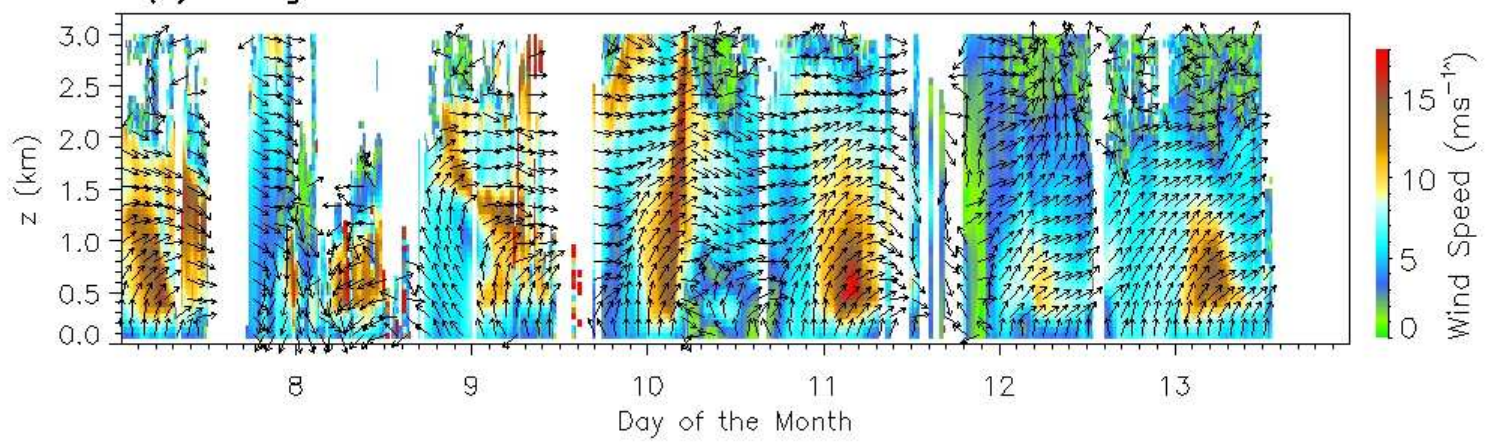

Figure 12. This is the same as Figure 11 except that the time period shown is from 7-13 May 2004. 


\subsection{PBL Height Estimates, CBH, and Surface Fluxes}

Figures 13 and 14 show time-height cross sections of the mean horizontal winds from the Annex lidar, (range-corrected) signal-to-noise ratio (SNR) from the Annex lidar, the vertical derivative of the (range-corrected) SNR, and time series of friction velocity and kinematic heat flux. The fluxes were measured at a site in the National Arboretum (DCnet), located approximately $10 \mathrm{~km}$ northeast of the Annex lidar. Time-height cross sections of range-corrected SNR were obtained by averaging all the beams within a given VAD and then converting range to height above ground. In this sense, each SNR profile in Figures 13 and 14 represent averages over a cone, where the scan elevation angle was $24^{\circ}$.

The range corrected SNR field provides a measure of the attenuated aerosol backscatter. Strong negative gradients in the SNR field indicate a decrease in the aerosol backscatter with height, while sharp positive gradients generally indicate cloud bases. The solid black curves in Figures 13b, 13c, 14b, and 14c represent estimates of the developing Convective Boundary Layer (CBL) height and the top of the residual layer height (Stull 1988), while the black squares represent estimates of cloud base height (CBH). The CBL heights (developing and residual) were estimated by visually locating the height of the maximum negative SNR gradient. In a separate analysis we found that the base of the capping inversion layer observed in radiosonde data correlated quite well with strong negative gradients in the SNR (Newsom et al. 2009).

Time-height cross sections of the SNR gradient often show two or more altitudes with distinct minima. Shortly after sunrise there is often a strong minimum just above the surface. This minimum is associated with the developing CBL, and increases rapidly during the early portion of the day. Examples of this are observed on the $1^{\text {st }}, 5^{\text {th }}, 6^{\text {th }}, 9^{\text {th }}, 10^{\text {th }}, 11^{\text {th }}, 12^{\text {th }}$ and $13^{\text {th }}$. On several days, this minimum continued to increase until about sunset. Secondary minima in the SNR gradient were also observed at higher altitudes. In some cases, these minima are remnants of the CBL height from previous days, i.e., residual layer heights. After sunset, the residual layer height usually decreases and the layer below becomes weakly stably stratified (Newsom et al. 2009). As a result, the aerosol distribution becomes less homogeneous with height, and it is more challenging to estimate the top of the residual layer. However, in many cases it was possible to track the top of the residual layer between adjacent diurnal periods.

Figures 13 and 14 indicate weather disturbances with low-level clouds propagating through the region on the $2^{\text {nd }}, 3^{\text {rd }}, 5^{\text {th }}$ and $8^{\text {th }}$. After 9 May 2004 the skies were mostly clear, temperatures warmed, and high pressure settled in. During this latter part of the field campaign the SNR and fluxes exhibited a more regular diurnal variation.

As noted previously, LLJ's were observed during every night of the field campaign with the exception of the $2^{\text {nd }}$ and the $6^{\text {th }}$. The surface friction velocity in Figures $13 \mathrm{~d}$ and $14 \mathrm{~d}$ show distinct local maxima during the nights of the $4^{\text {th }}, 10^{\text {th }}, 11^{\text {th }}$, and $13^{\text {th }}$. These maxima appear to be correlated with the presence of relatively strong LLJs. By contrast, only a very weak LLJ developed on the night of the $12^{\text {th }}$, and the friction velocity showed only a very weak nighttime maximum on that night. 

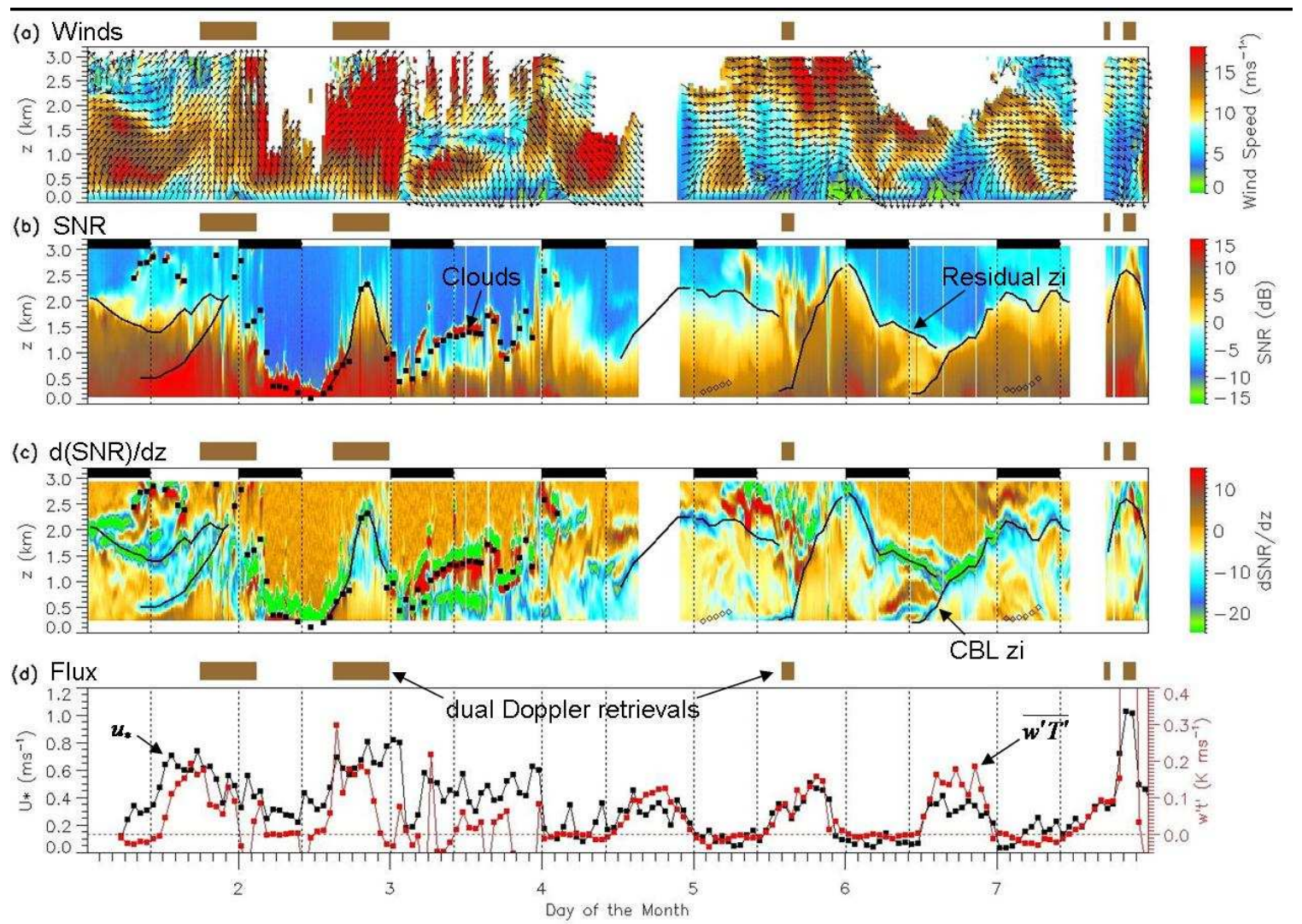

Figure 13. Boundary layer structure as observed by Annex lidar and surface flux station at the National Arboretum for the period from 1-7 May 2004. (a) Mean horizontal winds from a VAD analysis of the Annex lidar data; (b) SNR from the Annex lidar; (c) Vertical derivative of the SNR in (b); (d) Friction velocity (black) and kinematic heat flux (red) at the National Arboretum obtained through DCnet. The dark bars on top of panels (b) and (c) indicate the nighttime periods. In panels (b) and (c) cloud base heights $(\mathrm{CBH})$ are indicated by the black-filled squares, and boundary layer heights are indicated by the solid dark lines. The brown bars at the top of each panel indicate the times when valid dual-Doppler retrievals were obtained. 

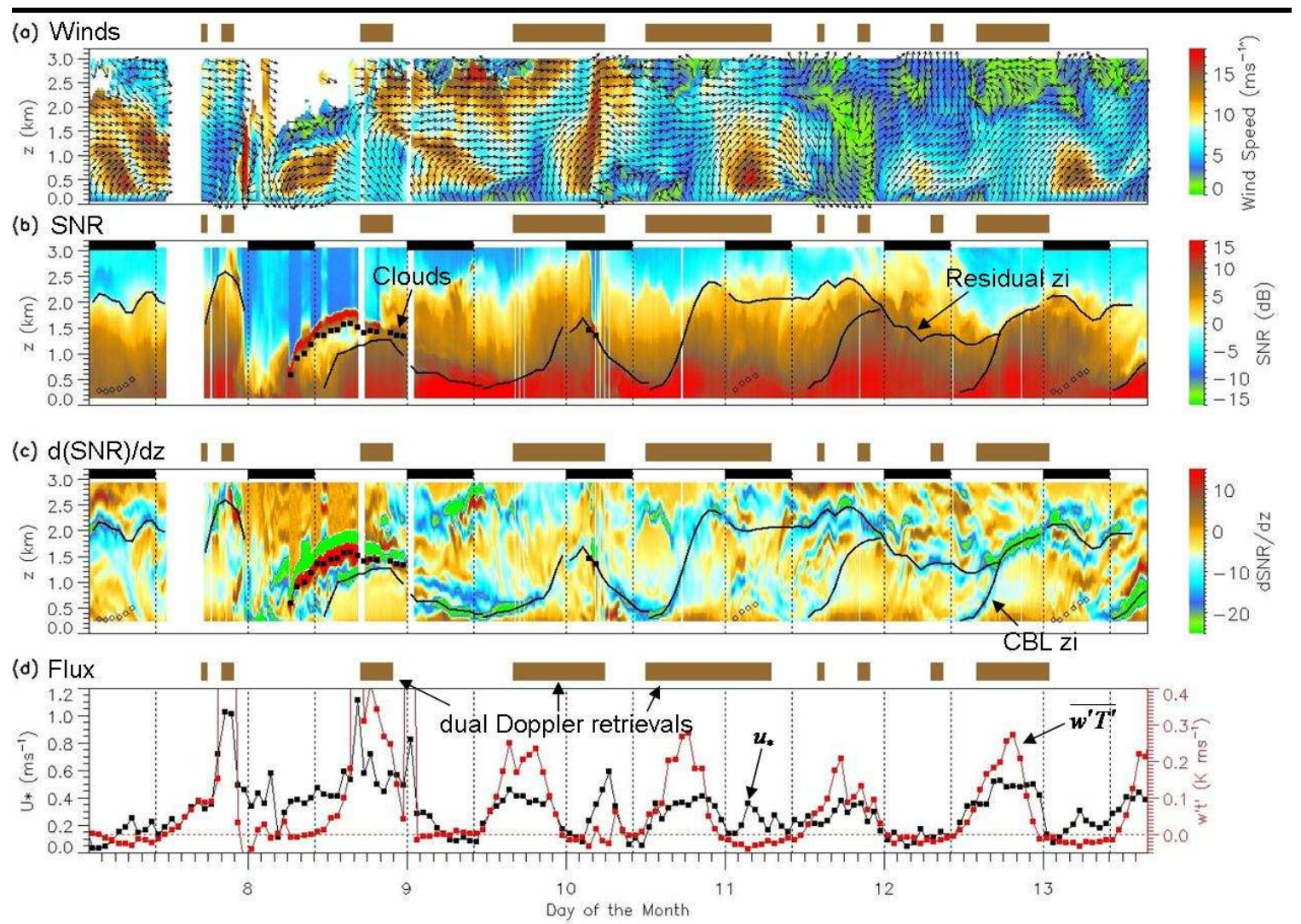

Figure 14. This is the same as Figure 13 except the period covers 7-13 May 2004. 



\subsection{DUAL-DOPPLER ANALYSIS}

Two methods for processing dual-Doppler lidar data were explored during the course of this field campaign. We initially attempted to apply techniques similar to those described by Newsom et al. (2008), and Hill et al. (2010). In these methods, which we refer to as least squares methods, turbulence structures are retrieved using scanning data with very fine spatial and temporal resolution. However, application of this methodology to the current dataset is problematic due to the relatively slow update rates of the volume scans ( $\sim 5$ minutes), and the data quality issues with the Bolling lidar.

As described in Section 3.1, numerous data voids resulted after quality control procedures were applied to the Bolling lidar data. The only effective method of dealing with these data voids was to apply sufficient temporal averaging, as was done in the VAD analysis. The dual-Doppler algorithm described in this section made use of considerable temporal averaging of the lidar data in order to retrieve the spatial variability of the mean velocity field.

Variable surface characteristics (i.e., variations in terrain, surface roughness, and/or thermal properties) will have impacts on the mean flow. In this case, the dual-Doppler overlap region covers an area in which the underlying surface exhibits abrupt transitions between a rough urban surface and a smooth water surface (see Figure 1). Thus, an objective of the current dual-Doppler analysis approach is to detect the response of the mean flow to these surface heterogeneities.

\subsection{Hourly Averaged Volume Scans}

Individual volume scans were averaged over one-hour periods. The averaging helped to suppress noisy fluctuations and improve the coverage for the Bolling lidar. The averaging was done using a prescribed azimuth grid at each elevation angle of the volume scans. Both the mean and second moment of the radial velocity field were computed. The second moment was used by the dual-Doppler algorithm to estimate horizontal velocity variances.

Both lidars were configured so that each volume scan required about 5 minutes to complete, thus, each elevation angle was revisited approximately 12 times during the course of any given hour. Although the range coordinate was fixed, the azimuth angles for a given elevation angle varied from one volume scan to the next. In order to average volume scans it was necessary to define a fixed azimuth grid. For this study, the radial velocity measurements were averaged using an azimuth grid with a resolution of $1^{\circ}$, and a range grid with a resolution equal to the raw range resolution $(72 \mathrm{~m})$. Radial velocity error variances were also computed by averaging within these azimuth and range cells. These hourly averaged volume scans were then saved to disk for later processing by the dual-Doppler algorithm.

\subsection{Velocity Retrieval}

Estimates of the horizontal velocity components were generated from the hourly averaged data set described above. The first step in this process involved defining the horizontal position of a so-called "virtual tower" (Calhoun et al. 2006). For each scan plane (elevation angle) and for each lidar, hourly averaged radial velocities were interpolated to the horizontal location of the virtual tower. This data was then interpolated to a high resolution vertical grid along the virtual tower, as illustrated in Figure 15. 
Missing values are assigned to those grid points that lie above the highest valid measurement or below the lowest valid measurement. The overlap between the two interpolated curves defines the valid layer over which the horizontal velocities are computed.

Given simultaneous and collocated radial velocity data from both lidars, the computation of the horizontal velocity components is straightforward. Radial velocities at a given point in space (and time) observed by lidars "1" and " 2 " can be written as

$$
\overline{u_{r 1}}=\overline{\mathbf{u}} \cdot \mathbf{r}_{1}=\bar{u} \cos \theta_{1} \sin \phi_{1}+\bar{v} \cos \theta_{1} \cos \phi_{1}
$$

and

$$
\overline{u_{r 2}}=\overline{\mathbf{u}} \cdot \mathbf{r}_{2}=\bar{u} \cos \theta_{2} \sin \phi_{2}+\bar{v} \cos \theta_{2} \cos \phi_{2},
$$

where $\phi$ and $\theta$ are the azimuth and elevation angles from the lidar to the observation point, and the subscripts refer to either lidar " 1 " or lidar " 2 ". The overbar is used to denote an hourly average. In equations (5.2.1) and (5.2.2) we have ignored the contribution from the hourly averaged vertical velocity component. This is a reasonable assumption as long as the vertical velocity is much smaller than the horizontal velocity, or the elevation angle is small. To simplify the notation we define the so-called "horizontal radial velocity" as

$$
u_{\rho}=u_{r} / \cos \theta
$$

Equations (5.2.1) and (5.2.2) can then be written as

$$
\overline{u_{\rho 1}}=\bar{u} \sin \phi_{1}+\bar{v} \cos \phi_{1}
$$

and

$$
\overline{u_{\rho 2}}=\bar{u} \sin \phi_{2}+\bar{v} \cos \phi_{2} .
$$

Solving for $\bar{u}$ and $\bar{v}$ yields

$$
\bar{u}=\frac{1}{\Delta}\left(\overline{u_{\rho 2}} \cos \phi_{1}-\overline{u_{\rho 1}} \cos \phi_{2}\right)
$$

and

$$
\bar{v}=\frac{1}{\Delta}\left(\overline{u_{\rho 1}} \sin \phi_{2}-\overline{u_{\rho 2}} \sin \phi_{1}\right),
$$

where

$$
\Delta=\sin \phi_{2} \cos \phi_{1}-\cos \phi_{2} \sin \phi_{1}
$$




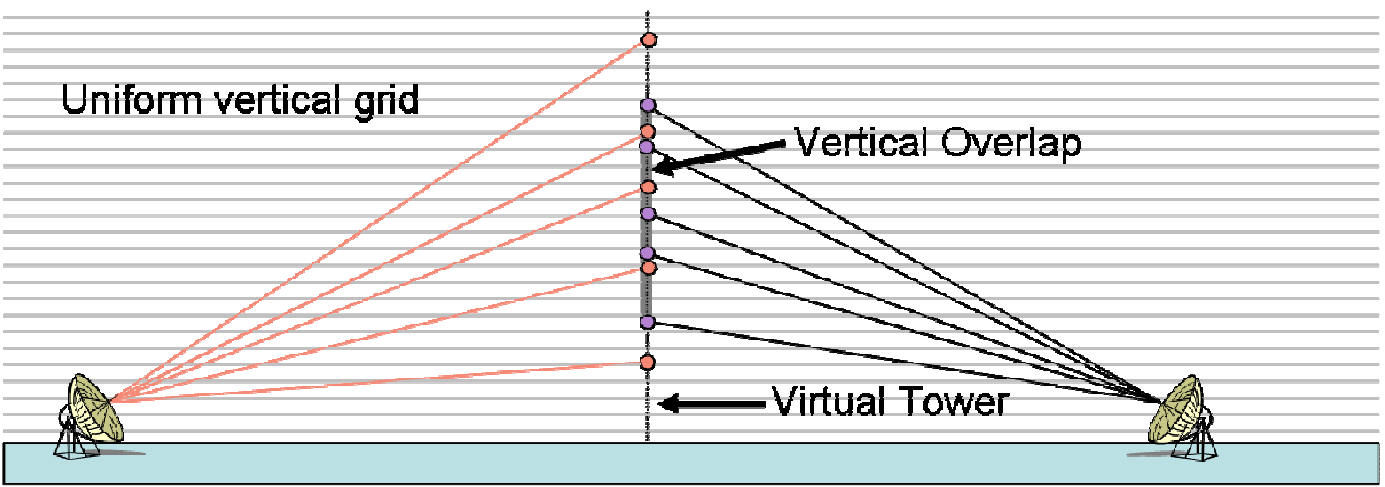

Figure 15. Schematic illustration of the dual-Doppler analysis method.

\subsection{Velocity Variance Retrieval}

Estimates of the variance in $u$ and $v$ were also computed from estimates of the variance in the horizontal radial velocities, $u_{\rho 1}$ and $u_{\rho 2}$. Velocity perturbations can be written as

$u^{\prime}=u-\bar{u}=\frac{1}{\Delta}\left(u_{\rho 2}^{\prime} \cos \phi_{1}-u_{\rho 1}^{\prime} \cos \phi_{2}\right)$

and

$v^{\prime}=v-\bar{v}=\frac{1}{\Delta}\left(u_{\rho 1}^{\prime} \sin \phi_{2}-u_{\rho 2}^{\prime} \sin \phi_{1}\right)$

Squaring equations (5.2.9) and (5.2.10) and averaging yields

$\overline{u^{\prime 2}}=\frac{1}{\Delta^{2}}\left(\overline{u_{\rho 2}^{\prime 2}} \cos ^{2} \phi_{1}+\overline{u_{\rho 1}^{\prime 2}} \cos ^{2} \phi_{2}-2 \overline{u_{\rho 2}^{\prime} u_{\rho 1}^{\prime}} \cos \phi_{1} \cos \phi_{2}\right)$

and

$\overline{v^{\prime 2}}=\frac{1}{\Delta^{2}}\left(\overline{u_{\rho 2}^{\prime 2}} \sin ^{2} \phi_{1}+\overline{u_{\rho 1}^{\prime 2}} \sin ^{2} \phi_{2}-2 \overline{u_{\rho 2}^{\prime} u_{\rho 1}^{\prime}} \sin \phi_{1} \sin \phi_{2}\right)$.

Thus, computation of the velocity variances requires knowledge of both the variance and covariance of the radial velocities. The radial velocity variances, $\overline{u_{\rho 1}^{\prime 2}}$ and $\overline{u_{\rho 2}^{\prime 2}}$, are computed by averaging the raw data, as described in Section 5.1. However, the covariance term, $\overline{u_{\rho 2}^{\prime} u_{\rho 1}^{\prime}}$, cannot be reliably estimated from the raw data, as this would require simultaneous and collocated measurements of $u_{\rho 1}$ and $u_{\rho 2}$. Instead, we assume that the covariance of the Cartesian components, $\overline{u^{\prime} v^{\prime}}$, is very much smaller than either of the variance terms, $\overline{u^{\prime 2}}$ or $\overline{v^{\prime 2}}$. Setting the covariance between $u$ and $v$ to zero, 
$\overline{u^{\prime} v^{\prime}}=\frac{1}{\Delta^{2}}\left(\overline{\left.u_{\rho 2}^{\prime} \cos \phi_{1}-u_{\rho 1}^{\prime} \cos \phi_{2}\right)\left(u_{\rho 1}^{\prime} \sin \phi_{2}-u_{\rho 2}^{\prime} \sin \phi_{1}\right)} \approx 0\right.$,

gives

$$
\overline{u_{\rho 1}^{\prime} u_{\rho 2}^{\prime}} \approx \frac{\overline{u_{\rho 2}^{\prime 2}} \cos \phi_{1} \sin \phi_{1}+\overline{u_{\rho 1}^{\prime 2}} \cos \phi_{2} \sin \phi_{2}}{\cos \phi_{1} \sin \phi_{2}+\cos \phi_{2} \sin \phi_{1}} .
$$

We define the total variance as

$$
\kappa=\overline{u^{\prime 2}}+\overline{v^{\prime 2}}
$$

For this study, total horizontal velocity variance is computed using equation (5.2.17), together with equations (5.2.11), (5.2.12) and (5.2.14). It is important to note that the total variance consists of contributions from both the atmosphere and noise in the measurement. If there is no correlation between the noise fluctuations and the (real) atmospheric fluctuations then the total variance can be expressed as a simple sum of the variance due to (real) atmospheric fluctuations, $\kappa_{\text {atmos }}$, and the variance due to instrumental noise, $\boldsymbol{\kappa}_{\text {inst }}$ (Lenchow et al. 2000), i.e.,

$$
\kappa=\kappa_{\text {atmos }}+\kappa_{\text {inst }},
$$

where the instrumental variance term is given by

$$
\kappa_{\text {inst }} \approx \frac{1}{\Delta^{2}}\left(\varepsilon_{\rho 1}^{2}+\varepsilon_{\rho 2}^{2}\right)
$$

Radial velocity error variances, $\varepsilon_{\rho 1}$ and $\varepsilon_{\rho 2}$, are the same as those described in Section 3.4. Equation (5.2.19) also assumes that noise fluctuations between the two lidars are uncorrelated. This is a very reasonable assumption. With $\kappa$ given by equation (5.2.18) and $\kappa_{\text {inst }}$ given by equation (5.2.19) it is then possible to estimate the atmospheric variance,

$$
\kappa_{\text {atmos }}=\kappa-\kappa_{\text {inst }} .
$$

\subsection{Three-dimensional Grid}

The procedure outlined above for retrieving velocity and velocity variance profiles from a single virtual tower can be repeated for any number of virtual towers in order to build a three-dimensional picture of the flow. For this study, we set up a two-dimensional grid of virtual towers over a portion of the dual-Doppler coverage area. This grid consisted of a 50 x 50 array of virtual towers over a 4 x $4 \mathrm{~km}$ domain. Three-dimensional arrays of the horizontal components, $u$ and $v$, as well as the instrument and atmospheric variances were stored to disk for later analysis. 


\subsection{DUAL-DOPPLER RESULTS}

The quality of individual wind retrievals was evaluated manually using custom three-dimensional visualization software developed in Interactive Data Language (IDL). The magnitude of the measurement noise was used as the primary metric to assess data quality. Wind retrievals with large measurement noise were rejected. In fact, the majority of wind retrievals were rejected largely due to the problems experienced by the Bolling lidar. The periods with valid retrievals are listed in Table 1. These periods are also indicated graphically by the brown bars at the tops of each panel in Figures 13 and 14.

Table 1. Start and end times for the periods containing valid dual-Doppler retrievals.

\begin{tabular}{|c|c|c|c|}
\hline \multicolumn{2}{|c|}{ Start Time (UTC) } & \multicolumn{2}{c|}{ End Time (UTC) } \\
\hline Date & Time & Date & Time \\
\hline 20040501 & 1900 & 20040502 & 0300 \\
\hline 20040502 & 1400 & 20040503 & 0030 \\
\hline 20040505 & 1400 & 20040505 & 1600 \\
\hline 20040507 & 1700 & 20040507 & 1800 \\
\hline 20040508 & 1700 & 20040508 & 2300 \\
\hline 20040509 & 1600 & 20040510 & 0600 \\
\hline 20040510 & 1200 & 20040511 & 0700 \\
\hline 20040511 & 1400 & 20040511 & 1500 \\
\hline 20040511 & 2000 & 20040512 & 0100 \\
\hline 20040512 & 0700 & 20040512 & 0900 \\
\hline 20040512 & 1400 & 20040513 & 0100 \\
\hline
\end{tabular}

Figures 16 through 20 show representative samples of vertical cross sections from the dual-Doppler analysis. These particular time periods were chosen because both lidars were operating well, and the measurement errors were relatively small. In all of these examples, the cross sections are taken along a 2 $\mathrm{km}$ west-to-east line that crosses the Potomac River, as indicated in the figures. The east side of the crosssection lies over East Potomac Park, and the west side lies over the western shore of the Potomac River just to the southeast of the Pentagon.

In addition to the wind speed and velocity variance, Figures 16 through 20 show the so-called wind direction deviation. This is defined as the difference between the wind direction at a point and the crosssection averaged wind direction. This quantity is computed using 


$$
\Delta \varphi=\tan ^{-1}\left(\frac{u \bar{v}-v \bar{u}}{u \bar{u}+v \bar{v}}\right)
$$

where $\bar{u}$ and $\bar{v}$ are the cross section average velocity components. Equation (6.1) yields deviations in the range $|\Delta \varphi| \leq 180^{\circ}$, such that positive values indicate winds that are rotated clockwise relative to the cross-section-averaged wind direction.

As noted in Section 4.1, southerly winds tended to dominate during the Pentagon Shield field campaign. For Figures 16, 17 and 20 the low level winds are southerly so that the cross sections are oriented roughly orthogonal to the mean low-level winds. In Figure 18 the low level winds are southwesterly, and the upper level winds are westerly. Figure 19 shows a relatively rare case in which the low winds were southeasterly.

The fetch over water is greatest for the southerly flow cases. In those cases, there is typically an enhancement of the velocity variance over the western shore of the Potomac, and in many cases, higher wind speeds over the water. The larger velocity variance over the western shore is likely due to the influence of the urban land surface in the upwind fetch. By contrast, the retrievals typically do not indicate an increase in the velocity variance over East Potomac Park. Again, this is likely due to the nature of the land surface over that portion of the cross section (mostly park land).

Figure 18 shows a case in which the low-level flow was southwesterly and the upper level (600 to $1000 \mathrm{~m}$ ) flow was westerly. In this case there appears to be an enhancement of the velocity variance at low levels over the river surface. The imagery suggests that this may be the result of disturbances created in the wake of the western shoreline. The wind direction deviation in Figure 18 shows an abrupt transition at the western shoreline, and exhibits the classic signature of an internal boundary (Stull 1988), with the depth of the counter-clockwise flow increasing with distance over the river.
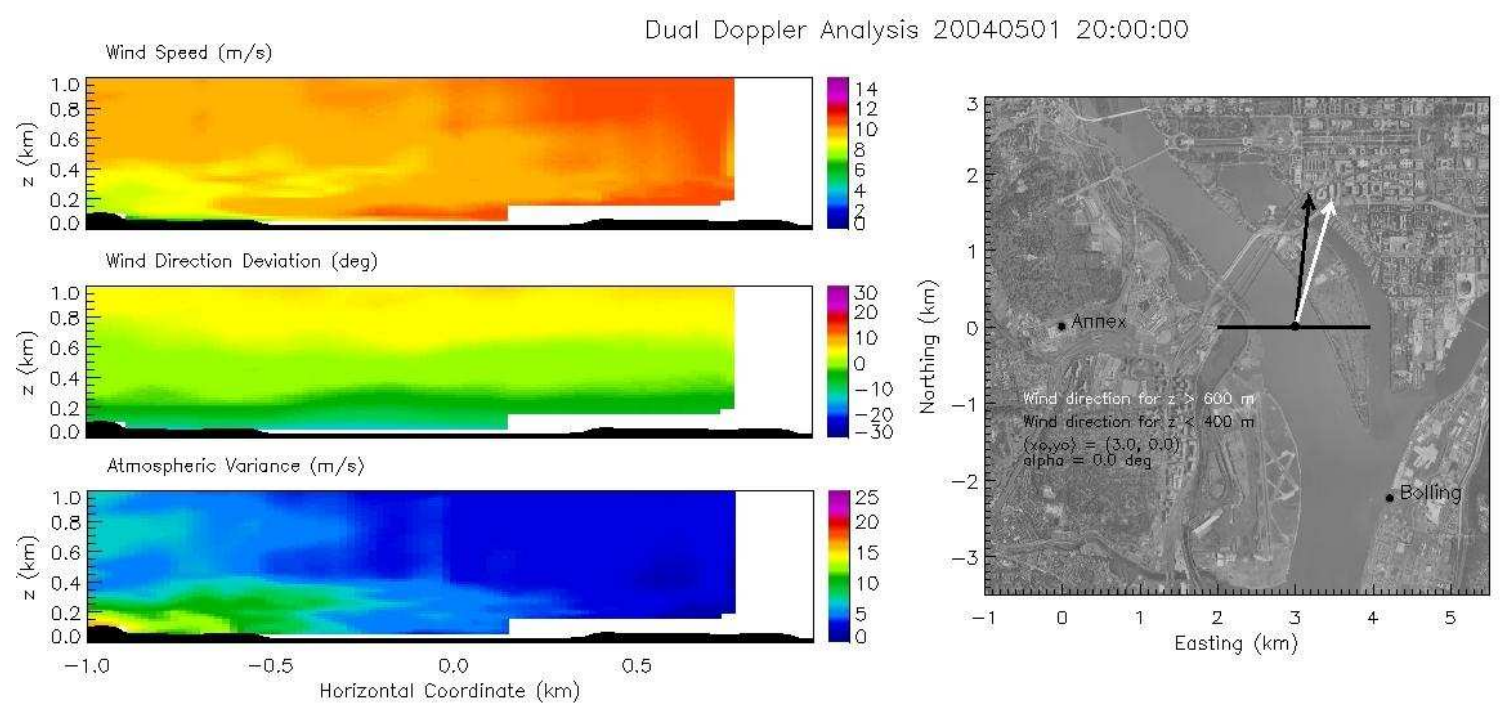

Figure 16. Vertical cross section of dual-Doppler derived (a) wind speed, (b) wind direction deviation, and (c) velocity variance at 20:00 UTC on 1 May 2004. Vertical cross sections are taken along a west-east line as indicated by the solid black line in the aerial view of panel (d). The horizontal coordinates in panels (a) through (c) indicate the west-to-east distance from the center of the cross section. Panel (d) also 
shows layer averaged wind directions for $0 \mathrm{~m} \leq z \leq 400 \mathrm{~m}$ (black arrow) and for $600 \mathrm{~m} \leq z \leq 1000 \mathrm{~m}$ (white arrow). Terrain profiles shown in panels (a) through (c) have been exaggerated (x20) for display purposes.
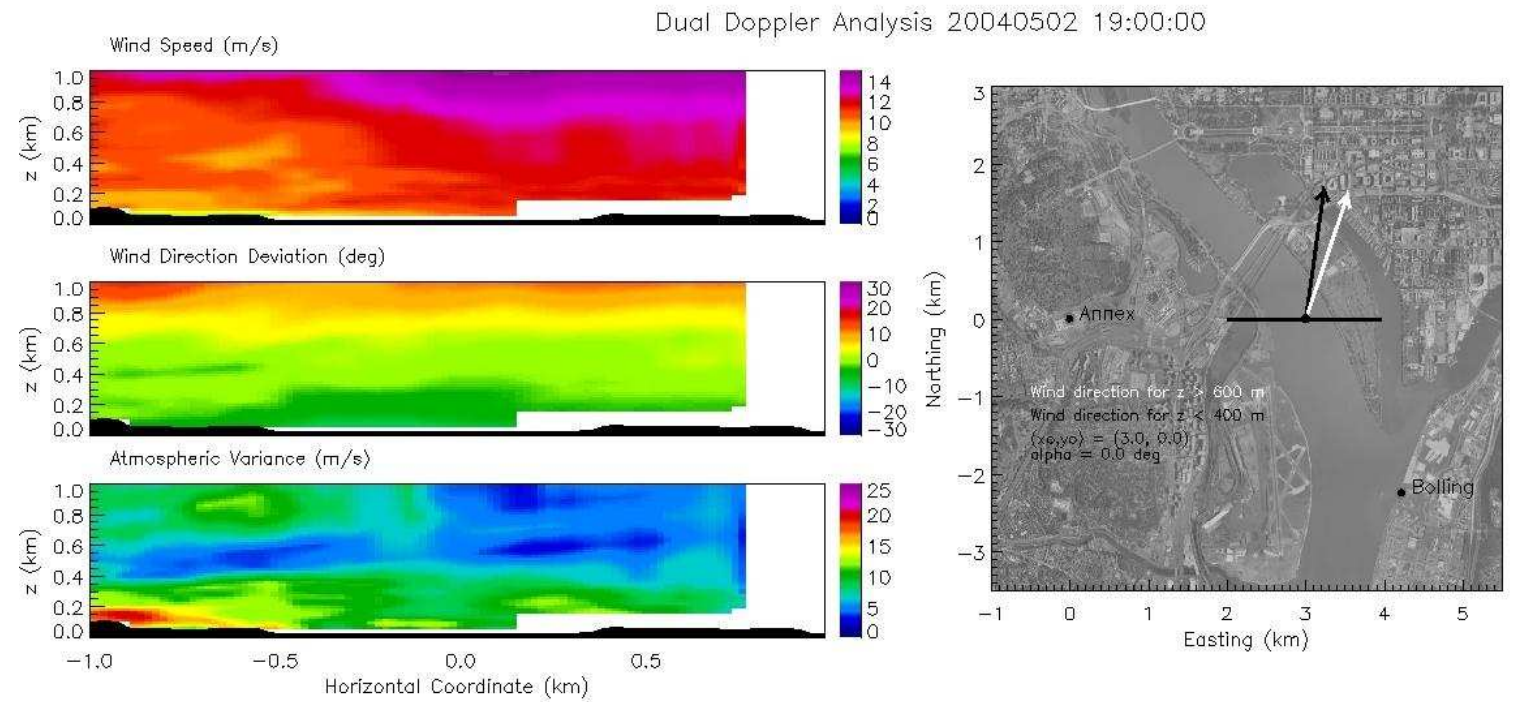

Figure 17. This is the same as Figure 16, except 19:00 UTC on 2 May 2004.
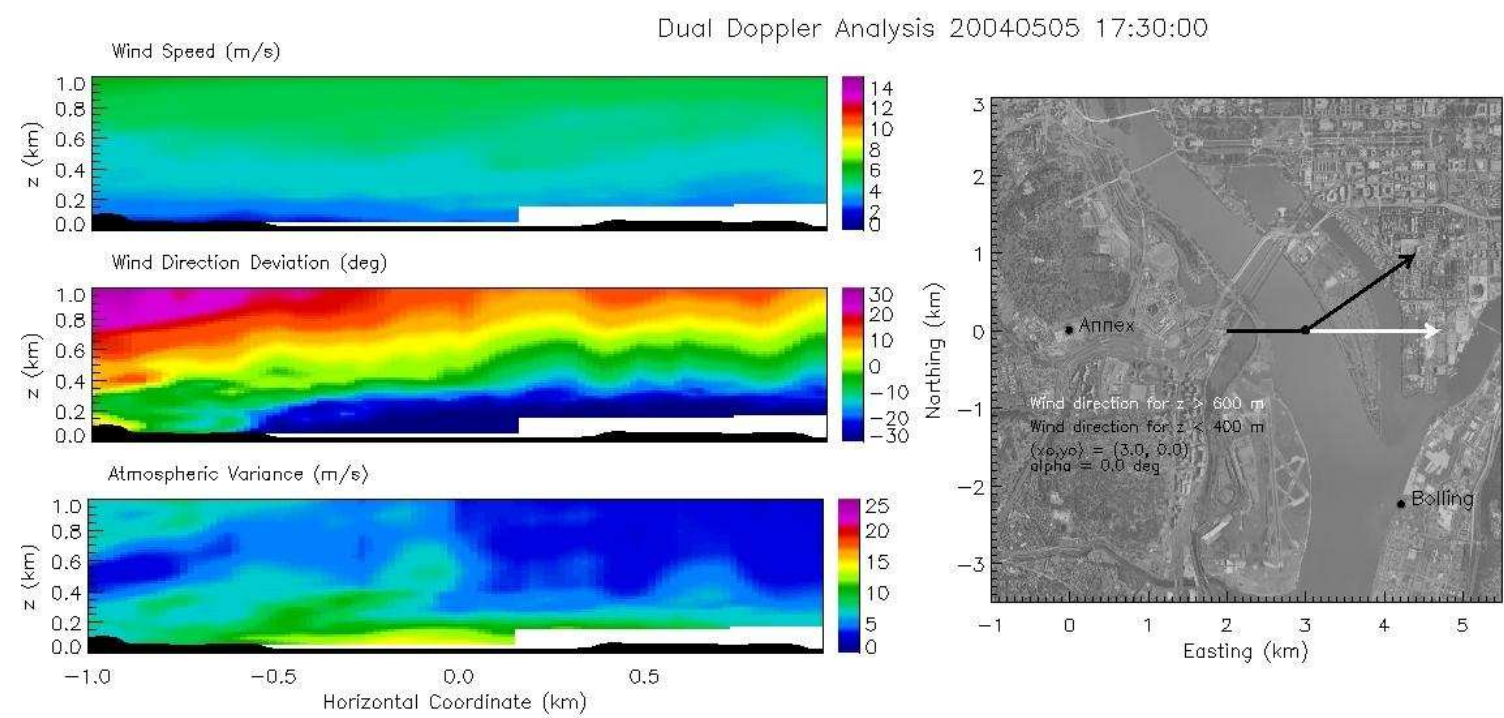

Figure 18. This is the same as Figure 16, except 17:30 UTC on 5 May 2004. 

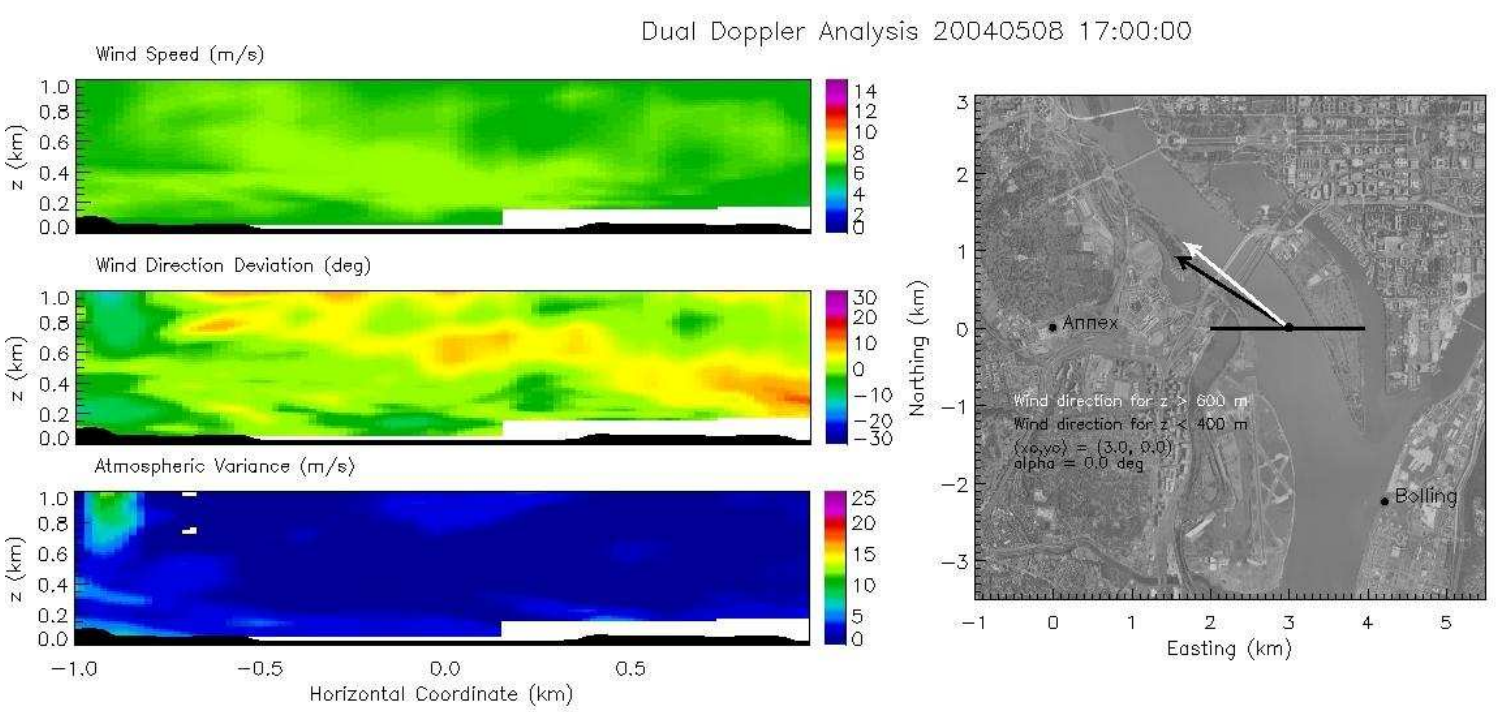

Figure 19. This is the same as Figure 16, except 17:00 UTC on 8 May 2004.
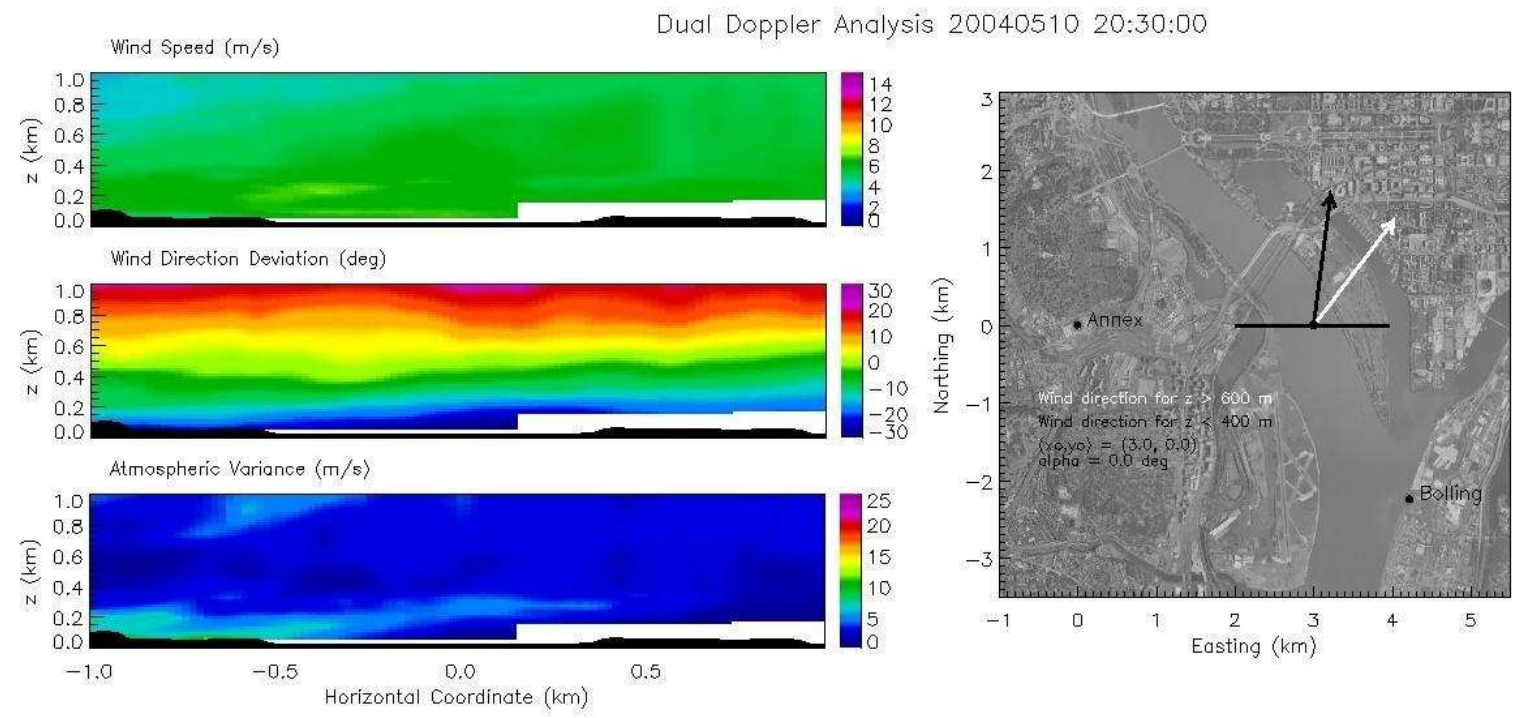

Figure 20. This is the same as Figure 16, except 20:30 UTC on 10 May 2004.

Dual-Doppler wind retrieval for all time periods listed in Table 1 were inspected manually using the three-dimensional visualization software described previously. Careful inspection of the dual-Doppler results revealed one very distinctive and consistent characteristic. Horizontal and vertical cross sections through the flow often indicated a region of higher speed winds over the river surface under southerly flow conditions. This flow feature is illustrated in Figures 21 through 23. These figures display representative examples of horizontal cross sections of wind speed in which there was southerly flow. These examples show stronger winds on the east side of the retrievals, over the river and extending northward over the eastern and southern portion of East Potomac Park. The transition between the lower and higher speed flow is roughly oriented along a north-south line, and the wind speed difference is most prominent at lower levels, i.e., below $\sim 200 \mathrm{~m}$ above ground level (AGL). 

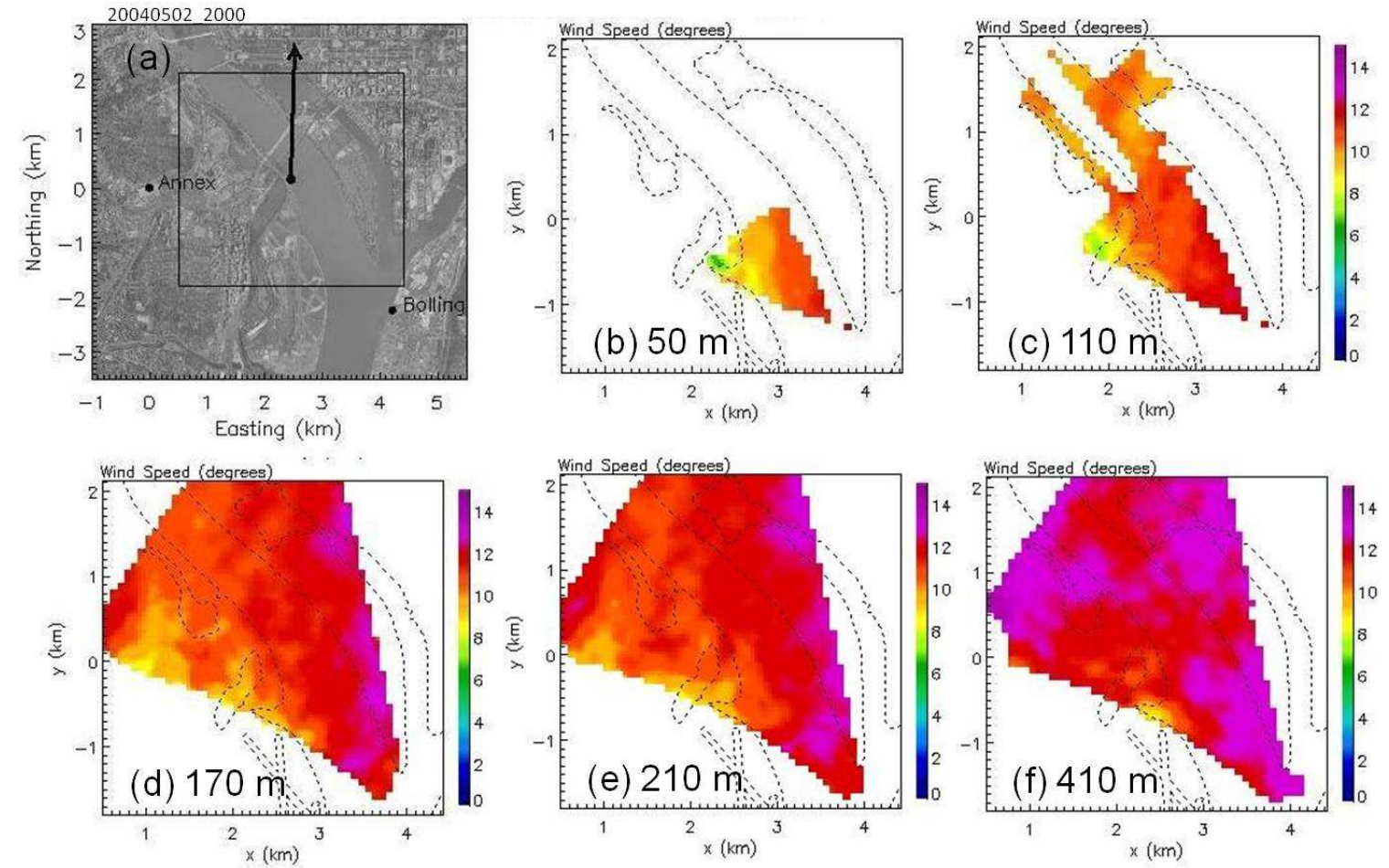

Figure 21. Panels (b) through (f) show horizontal cross-sections of wind speed from the dual-Doppler analysis for 2000 UTC on 12 May 2004. The heights (in MSL) are indicated in each panel. Panel (a) displays an aerial view of the study area. Also shown in panel (a) is the computation domain boundary, the lidar locations, and the mean wind direction at $50 \mathrm{~m}$ (solid black arrow).
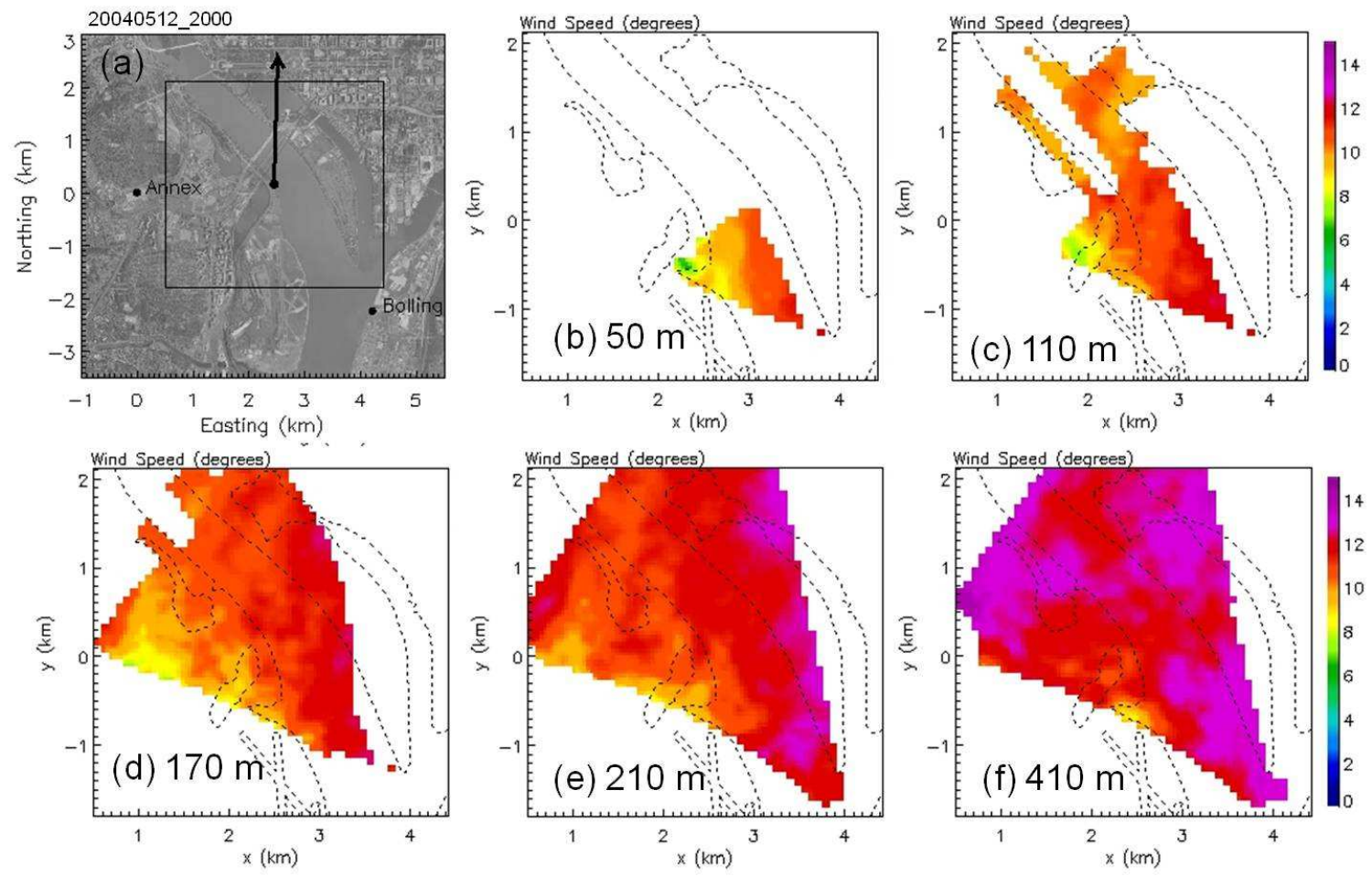

Figure 22. This is the same as Figure 21 except the time period is 2000 UTC on 12 May 2004. 

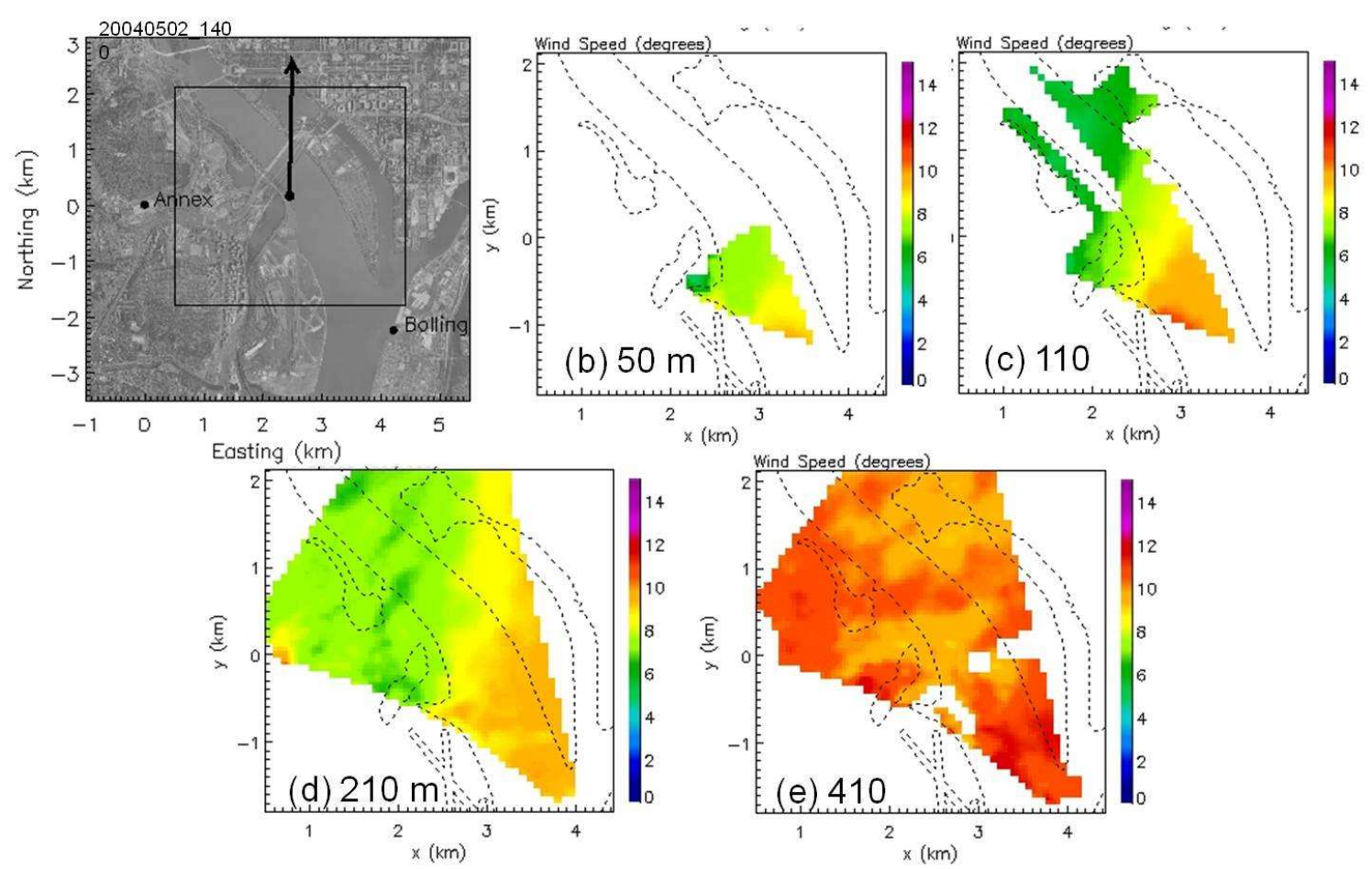

Figure 23. This is the same as Figure 21 except the time period is 1400 UTC on 2 May 2004.

The flow features illustrated in Figures 21 through 23 are likely the result of an acceleration in the wind over the water surface due to a differential in the roughness length with land surface, and the long fetch over water in upwind direction when the large-scale flow is southerly. The length and orientation of the upwind fetch appears to be quite important, as this effect was only consistently observed for southerly flows.

The reason for the observed flow behavior is easily understood by looking at the local geography. Figure 24 displays a map of the current study area and the region to the south. In the vicinity of the I-395 bridge, the Potomac River flows toward the southeast. The river widens considerably below this bridge. At the confluence with the Anacostia, the Potomac turns more toward the south, and continues along this direction for approximately $15 \mathrm{~km}$ until turning toward the west at Fort Hunt National Park.

Figure 24 clearly shows that when the winds are southerly, the upstream fetch over the eastern portion of the study area will be dominated by the relatively smooth river surface to the south. The long upstream fetch allows for significant linear acceleration of the flow over the river. Figures 21 through 23 also indicate that the higher speed southerly flow appears to retain significant inertia as it propagates northward over East Potomac Park and into the National Mall area. 


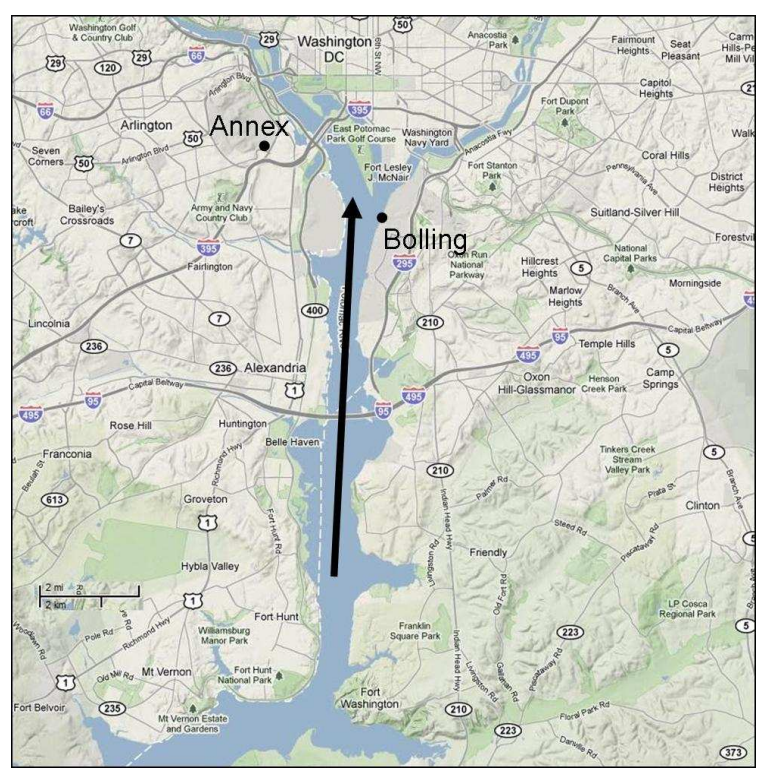

Figure 24. Large-scale map of the field study site. The long arrow indicates the relatively long fetch over water available to southerly flows. 



\subsection{VALIDATION OF THE DUAL-DOPPLER RETRIEVALS}

As a cross-check of the dual-Doppler wind retrievals, we examined individual radial velocity scans to assess whether the observed radial velocity fields were consistent with the river-induced wind speed differentials described in the previous section. We also compared area-constrained VAD winds from the Bolling and Annex lidars as an additional validation check.

\subsection{Comparion between Radial Velocity Scans}

Figure 25 shows a comparison between hourly averaged radial velocity scans from the Annex lidar, and the Bolling lidar for 2030 UTC on 2 May 2004. This figure shows hourly averaged radial velocity data for the lowest elevation angles that were performed by each lidar. There are several features worth pointing out. First, there is a general southerly flow, as was typical during the field campaign. Second, we observe a region of relatively strong negative radial velocity in the Annex data over the river and just to the north side of the runways at Reagan-National Airport. By contrast, the radial velocity at the same azimuth closer to the lidar is less negative, as indicated in Figure 25a. This suggests that the wind speed is larger over the river and runway surfaces than over the heavily urbanized areas closer to the lidar. Additionally, the fact that the Annex elevation angle is below the horizon suggests that the difference in wind speeds over the urban area and the river may be even more pronounced than indicated, since one would expect a decrease in wind speed with altitude.

Inspection of the Bolling lidar scan in Figure 25b shows two distinct north-south linear features in the radial velocity pattern. First, a primary feature was observed that corresponds to an abrupt decrease in the radial velocity along a north-south line over the river north of the airport runway. A secondary linear feature was also observed along a line that appears to extend north from the boundary between the airport and the river. Both of these features are consistent with relatively abrupt changes in wind speed due to changes in the roughness length in the upstream fetch. At the secondary transition there is a decrease in the wind speed toward the west just downwind of the boundary between the airport and the river. Between the secondary and primary transitions the upstream fetch is heavily influenced by the airport runway. As one moves west from the primary transition the wind speed decreases again because the upstream fetch is influenced by the rough urban surfaces to the south. 


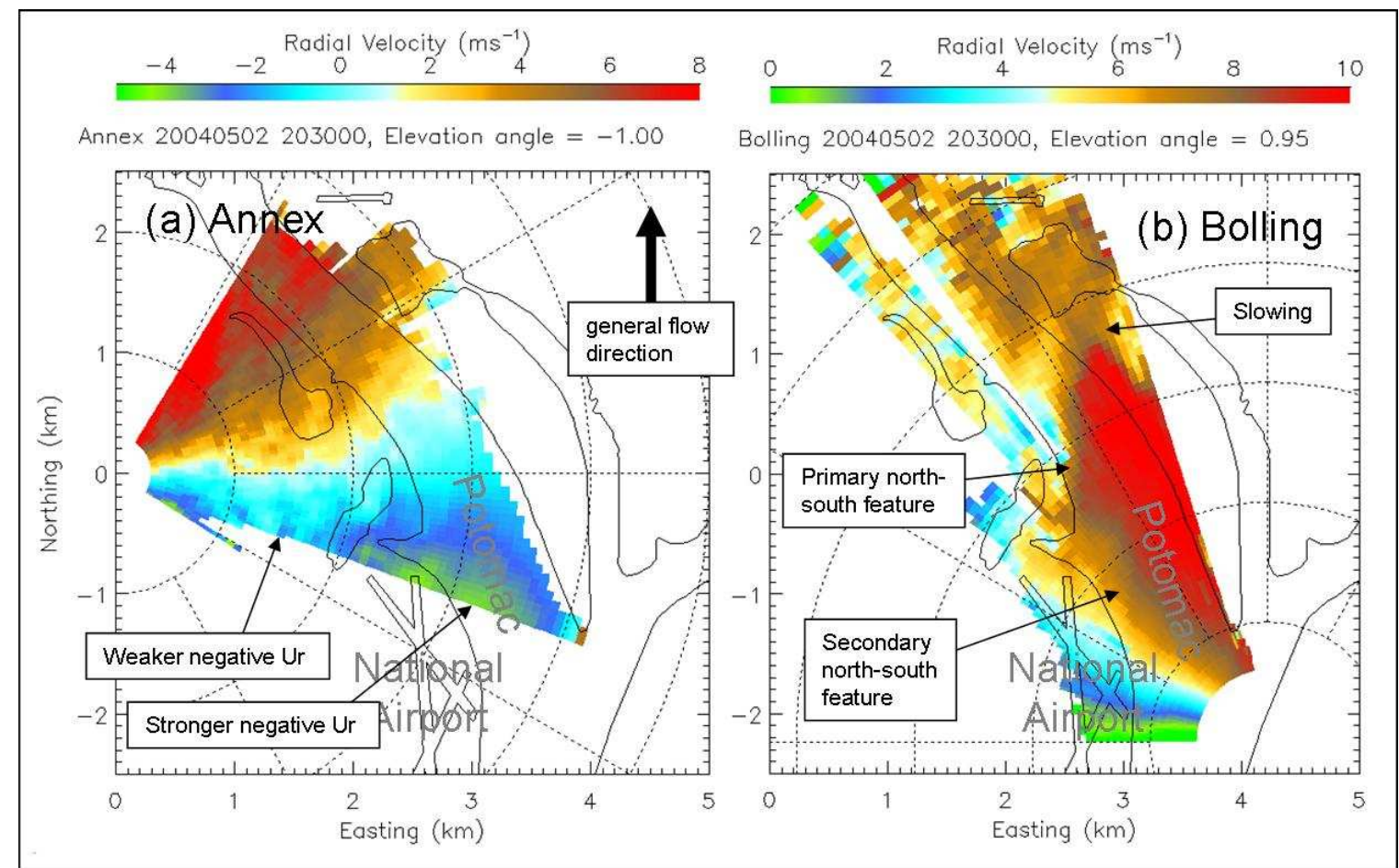

Figure 25. Comparison between hourly averaged radial velocity scans from (a) the Annex lidar, and (b) the Bolling lidar for 2030 UTC on 2 May 2004. The lowest elevation scans for both lidars are shown. The lowest elevation angle for the Annex lidar was $-1^{\circ}$, and the lowest elevation angle for the Bolling lidar was $0.95^{\circ}$. Note the difference in color scales between panels (a) and (b).

\subsection{Comparison between area-constrained VAD results}

As an additional cross-check of the dual-Doppler wind retrievals, we compared so-called areaconstrained VAD winds from the Bolling and Annex lidars. In contrast to the VAD results that were initially presented in Section 4.1, the area-constrained VAD winds are computed by using only radial velocity data that falls within a predefined horizontal range from the lidar. The idea is to develop wind profiles that are more representative of the column immediately above the lidar. In this particular case, the maximum horizontal range was limited to $1 \mathrm{~km}$ for both lidars, as illustrated in Figure 26. Additionally, the Bolling lidar's azimuth angles were constrained to use only observations over the river, as indicated in Figure 26. By imposing these constraints, the idea is that the Annex wind profiles are representative of a heavily urbanized area and the Bolling wind profiles are representative of the flow immediately above the river surface. 


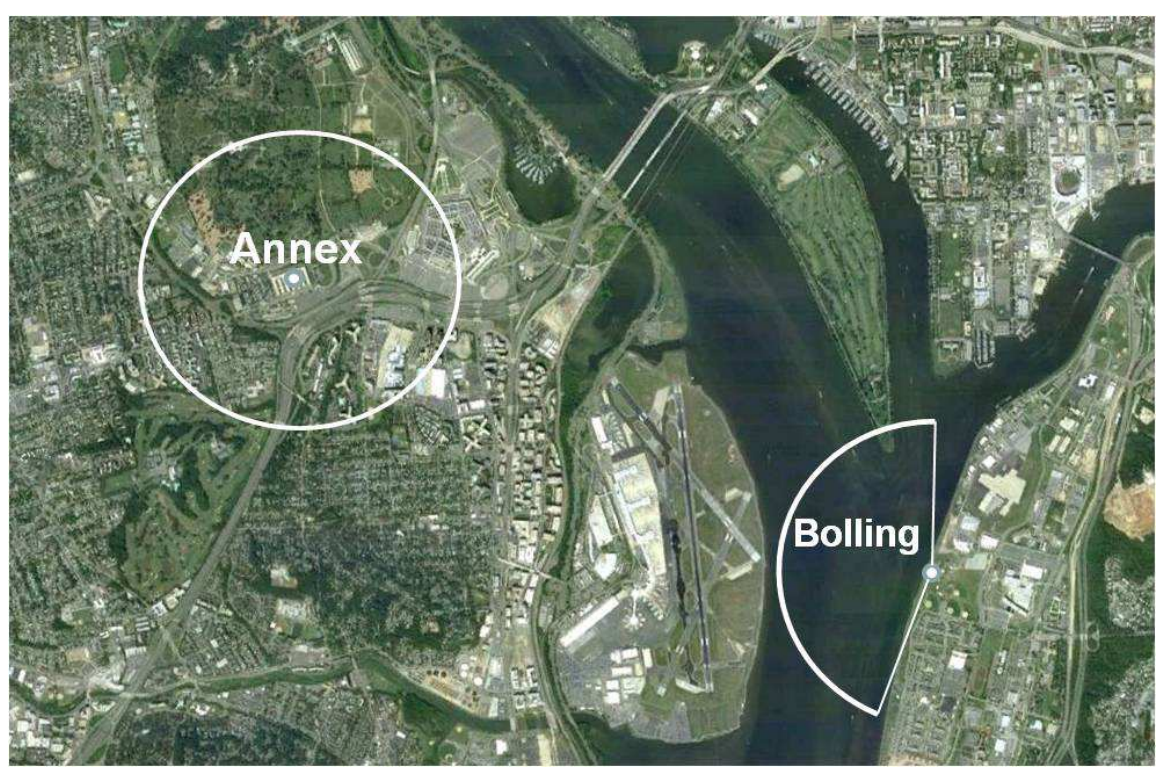

Figure 26. Horizontal coverage of the area-constrained VADs for the Annex and Bolling lidars. Wind speed differences between the Bolling and Annex lidars were computed by limiting the maximum horizontal range of the data used in the computation of the wind speed profiles. The maximum horizontal range was set to $1 \mathrm{~km}$.

Figures 27 and 28 show differences in the area-constrained VAD wind speeds between the Bolling and Annex lidars. Positive differences imply that the Bolling winds are stronger than the Annex winds. These figures clearly show that positive differences occur when the overall flow is southerly. The correlation between southerly flow and positive wind speed difference is most apparent below about 150 $\mathrm{m}$ above mean sea level (MSL).

The wind speed difference shown in Figures 27 and 28 generally confirm observations from the dualDoppler retrievals. Nevertheless, there are a few periods when the southerly flow and the differences are approximately zero or negative above $100 \mathrm{~m}$ MSL. We note that these periods tend to coincide with the presence of LLJs. There is some evidence in the data to suggest that the acceleration of the flow immediately above the river surface is impeded by strong directional shear aloft. Further analysis should be conducted to investigate this hypothesis.

For wind directions other than southerly, the wind speed differences are highly variable, but the results indicate a slight negative bias. This would imply a tendency for higher speed flows, at the same altitude, over the slightly higher terrain of the Annex lidar than over the Bolling lidar. This maybe the result of terrain induced acceleration of the flow (Reisner and Smolarkiewicz 1994; Hunt and Snyder, 1980). 
o) Bolling-Annex Wind Speed Difference $\left(\mathrm{ms}^{-1}\right)$

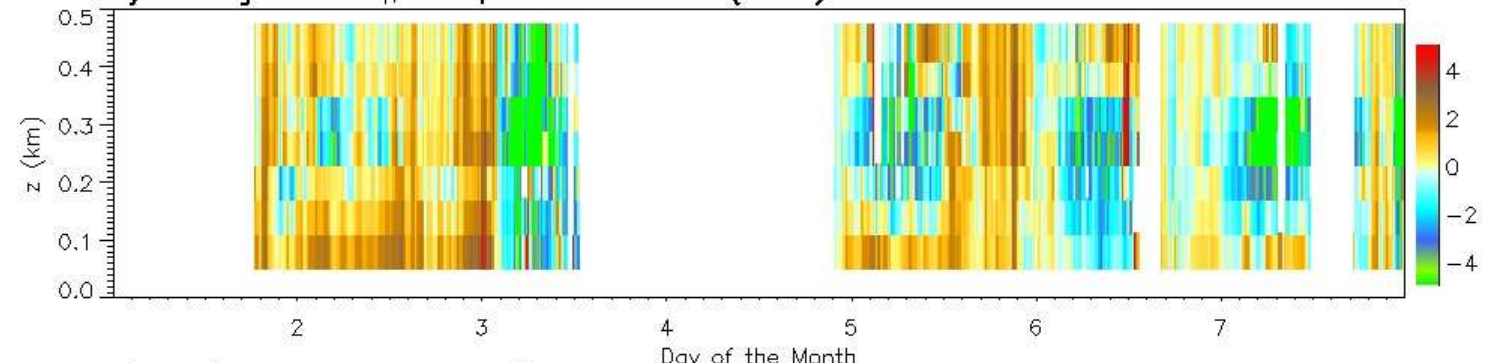

b) Bolling-Annex Relative Wind Speed Difference
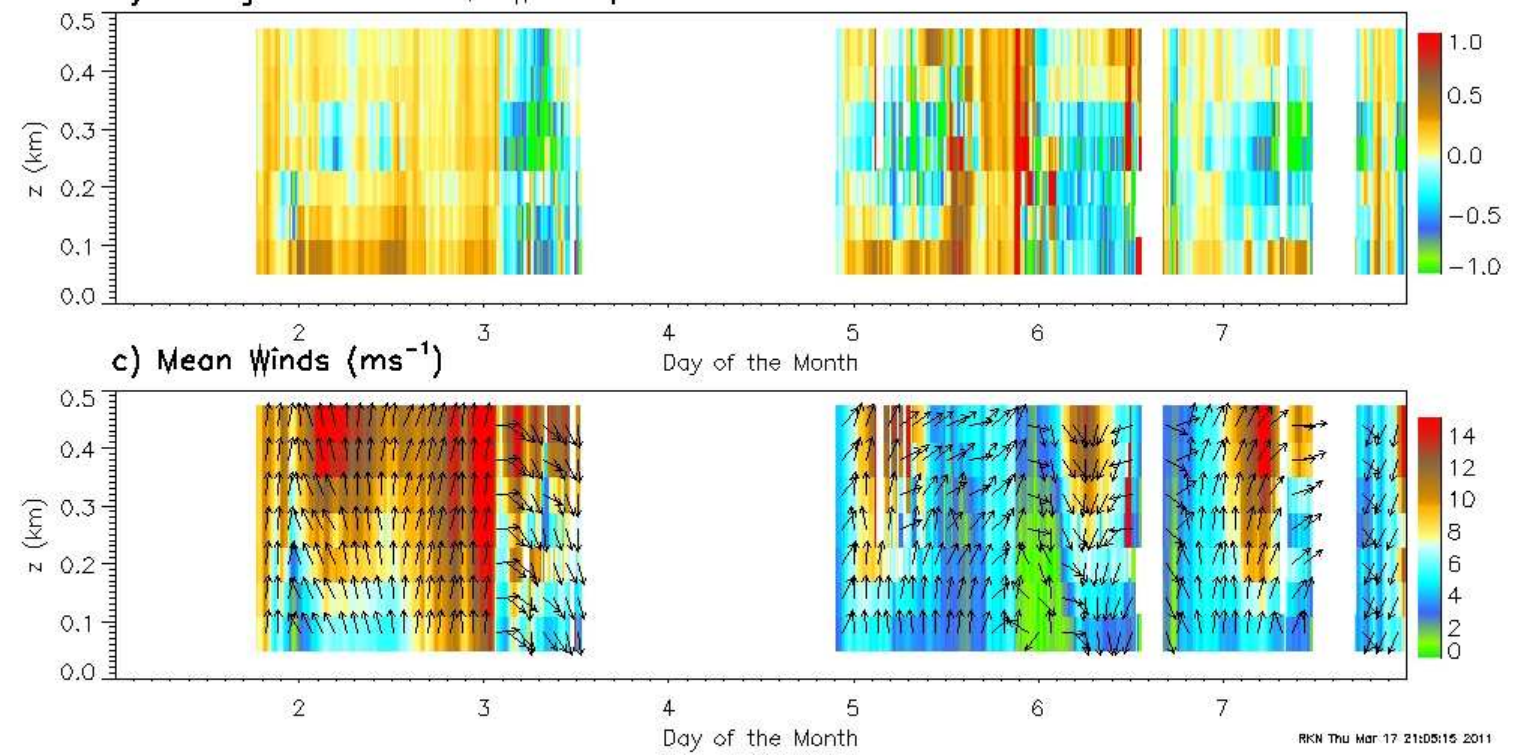

Figure 27. (a) Absolute and (b) Relative wind speed differences between the Bolling and Annex lidars for the period from 1-7 May 2004. Panel (c) shows the wind speed and direction from the average of the Annex and Bolling VAD wind components. Heights are in MSL. 
o) Bolling-Annex Wind Speed Difference $\left(\mathrm{ms}^{-1}\right)$

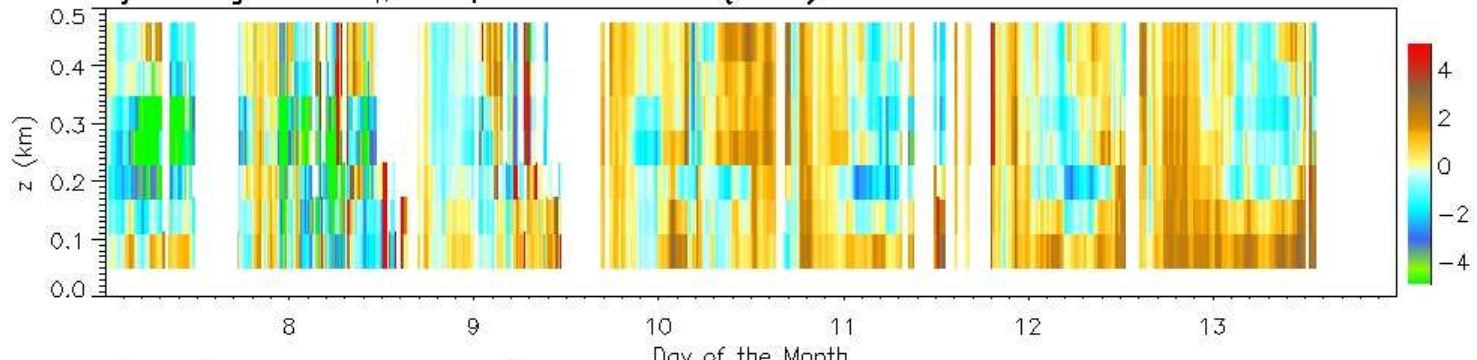

b) Bolling-Annex Relative Wind Speed Difference

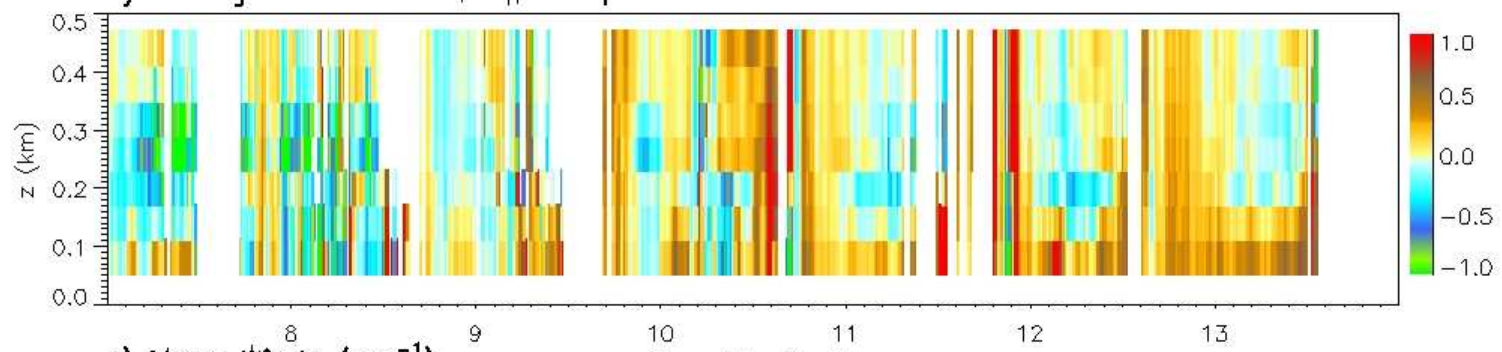

c) Mean Winds $\left(\mathrm{ms}^{-1}\right)$

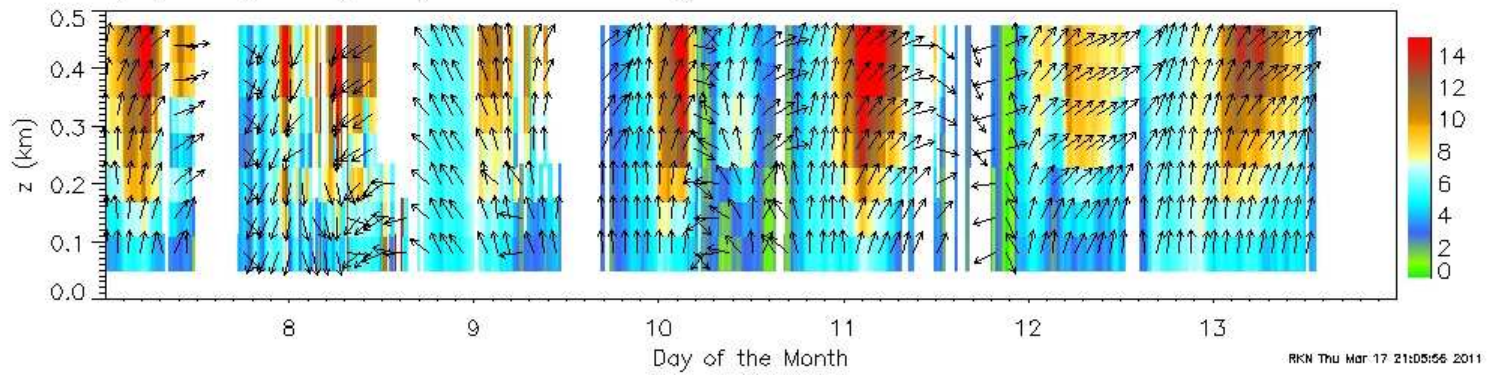

Figure 28. This is the same as Figure 27 except the period is for 7-13 May 2004. 



\subsection{SUMMARY}

This report described work that was conducted to analyze Doppler lidar data collected during the Pentagon Shield field campaign. The focus of this work was to use the data from the lidars in conjunction with other sensors to:

1) Characterize the overall boundary-layer structure

2) Generate highly resolved wind retrievals from the dual-Doppler lidar scans

3) Analyze the results of the dual-Doppler retrievals in order to understand the dominant flow characteristics over the study area during the field campaign.

One of the technical challenges in this project involved dealing with the performance limitations of the Bolling lidar. The Bolling lidar experienced frequent periods of degraded performance, particularly at night. As a result, particular attention was paid to data quality control procedures. This report described in detail the various quality control methods that were applied to data. Quality control involved filtering out radial velocity data corresponding to abnormally low laser pulse energies, low SNR, and fixed hard target returns. Estimates of measurement error were also made in order to in order to determine the atmospheric contribution to velocity variance in the dual-Doppler analysis.

For this study we used a modified VAD analysis to compute mean wind profiles from both the Bolling and Annex lidars over the course of the two week field campaign. By applying a 30-minute average to the raw data, positive agreement was achieved between the Annex and Bolling VAD winds, despite the problems with the Bolling lidar.

Analysis of the VAD winds generally indicate that under fair weather conditions a southerly flow tended to dominate, although there were several periods where weather disturbances modified this tendency. Low-level jet (LLJ) structures were evident on all but two of the nights during the field campaign. The LLJs tended to form a couple of hours after sunset and reached maximum strength between 03 and 07 UTC.

As noted previously, LLJ's were observed during every night of the field campaign with the exception of the $2^{\text {nd }}$ and the $6^{\text {th }}$. The surface friction velocities show distinct local maxima during the nights of the $4^{\text {th }}, 10^{\text {th }}, 11^{\text {th }}$, and $13^{\text {th }}$. These maxima appear to be correlated with the presence of relatively strong LLJs. By contrast, only a very weak LLJ developed on the night of the $12^{\text {th }}$, and the friction velocity shows only a very weak nighttime maximum on that night.

Analysis of the Annex lidar's SNR field was used to estimate CBL and residual layer heights. On several days we observed a strong minimum in the vertical gradient of SNR just above the surface after sunrise. This minimum is associated with the developing CBL, and increases rapidly during the early portion of the daytime period. On several days, this minimum continues to increase until about sunset. Secondary minima in the SNR gradient were also observed at higher altitudes, and are believed to be remnants of the CBL height from previous days, i.e., the residual layer height.

The dual-Doppler analysis technique used in this study makes use of hourly averaged radial velocity data in order to suppress noise, and improve data coverage for the Bolling lidar. This analysis produced 
estimates of the two orthogonal horizontal velocity components, and the atmospheric contribution to the total horizontal velocity variance along a vertical line that we refer to as a virtual tower. A threedimensional picture of the flow is developed by simply repeating this computation for any number of virtual towers. For this study, we set up a two-dimensional grid of virtual towers over a portion of the dual-Doppler coverage area.

Inspection of horizontal and vertical cross sections of the dual-Doppler wind retrievals often indicated a region of higher speed winds over the river surface under southerly flow conditions. The transition between the lower and higher speed flow is roughly oriented along a north-south line, and the wind speed difference is most prominent at lower levels, i.e., below $\sim 200 \mathrm{~m}$ above ground level AGL. It is believed that this feature is the result of an acceleration in the wind due to the reduced drag over the water surface, and the long linear fetch south of the study area. The dual-Doppler results also suggest that this flow retains significant inertia as it propagates northward over East Potomac Park and into the National Mall area.

An area-constrained VAD analysis was conducted in an effort to confirm the dual-Doppler wind retrievals. This analysis was used to estimate differences in wind speed profiles over the urban land surface near the Annex lidar, and water surface near the Bolling lidar. The results generally confirmed the observations from the dual-Doppler analysis. Below $100 \mathrm{~m}$ MSL, wind speeds near the Bolling site were consistently larger than at the Annex site when the overall flow is southerly. Above this level, the trend was somewhat less obvious. The data suggests that the depth of the wind speed maximum over the river may be reduced by strong directional shear aloft, but additional analysis is required to confirm this hypothesis. 




\section{Appendix A References}

Banta RM, RK Newsom, JK Lundquist, YL Pichugina, RL Coulter, and LD Mahrt. 2002. "Nocturnal Low-Level Jet Characteristics over Kansas during CASES-99.” Boundary-Layer Meteorology 105(2): 221-252.

Blackadar AK. 1957. "Boundary Layer Wind Maxima and their Significance for the Growth of Nocturnal Inversions.” Bulletin American Meteorological Society 38(5): 283-290.

Bonner WD. 1968. "Climatology of the Low Level Jet.” Monthly Weather Review 96(12): 833-850.

Browning KA and R Wexler. 1968. "The Determination of Kinematic Properties of a Wind Field Using Doppler Radar.” Journal of Applied Meteorology 7(1): 105-113.

Calhoun R, R Waskowsky, R Heap, P Phelan, M Princevac, RK Newsom, H Fernando, and D Ligon. 2006. "Virtual Towers using Coherent Doppler Lidar during JU2003." Journal of Applied Meteorology and Climatology 45(8): 1116-1126.

Collier CG, F Davies, KE Bozier, AR Holt, DR Middleton, GN Pearson, S Siemen, DV Willetts, GJG Upton, and RI Young. 2005. "Dual-Doppler Lidar Measurements for Improving Dispersion Models." Bulletin of the America Meteorological Society 86(6): 825-838.

Frehlich R. 2001. "Estimation of Velocity Error for Doppler Lidar Measurements.” Journal of Atmospheric Oceanic Technology 18: 1628-1639.

Frehlich R. 2004. "Velocity Error for Coherent Doppler Lidar with Pulse Accumulation." Journal of Atmospheric Oceanic Technology 21: 905-920.

Frehlich R, SM Hannon, and SW Henderson. 1997. "Coherent Doppler Lidar Measurements of Winds in the Weak Signal Regime.” Applied Optics 36(15): 3491-3499.

Henderson SW, CP Hale, JR Magee, MJ Kavaya, and AV Huffaker. 1991. "Eye-safe Coherent Laser Radar System at 2.1 $\mu \mathrm{m}$ using TmHo:YAG Lasers.” Optics Letters 16(10): 773-775.

Henderson SW, PJM Sunni, CP. Hale, SM Hannon, JR Magee, DL Bruns, and EH Yuen. 1993. "Coherent Laser Radar at $2 \mu \mathrm{m}$ using Solid-State lasers." IEEE Geoscience and Remote Sensing Society 31(1): 4-15.

Hill M, R Calhoun, HJS Fernando, A Wieser, A Dörnbrack, M Weissmann, G Mayr, and R Newsom. 2010. "Coplanar Doppler Lidar Retrieval of Rotors from T-REX." Journal of the Atmospheric Science, 67(3): 713-729.

Hunt JC and WH Snyder. 1980. "Experiments on Stably and Neutrally Stratified Flow over a Model Three-Dimensional Hill.” Journal of Fluid Mechanics 96: 671-704 
Lenschow DH, V Wulfmeyer, and C Senff. 2000. "Measuring Second-Through Fourth-Order Moments in Noisy Data." Journal of Atmospheric and Oceanic Technology 17(10): 1330-1347.

Lothon M, DH Lenschow, and SD Mayor. 2006. "Coherence and Scale of Vertical Velocity in the Convective Boundary Layer from a Doppler Lidar." Boundary-Layer Meteorology 121: 521-536.

Lothon M., DH Lenschow, SD Mayor. 2009. "Doppler Lidar Measurements of Vertical Velocity Spectra in the Convective Planetary Boundary Layer." Boundary-Layer Meteorology 132: 205-226.

Mitchell MJ, RW Arritt, and K Labas. 1995. "A Climatology of the Warm Season Great Plains LowLevel Jet Using Wind Profiler Observations.” Weather and Forecasting 10(3): 576-591.

Newsom RK, R Calhoun, D Ligon, and J Allwine. 2008. "Linearly Organized Turbulence Structures Observed over a Suburban Area by Dual-Doppler Lidar." Boundary-Layer Meteorology 127: 111-130.

Newsom R, D Ligon, D Garvey. 2009. "Dual-Doppler Lidar Observations Over Washington DC." 4th Symposium on Lidar Atmospheric Applications, Phoenix, AZ, 11-15 January 2009. American Meteorological Society, Boston.

Newsom R, D Ligon, and D Garvey. 2011. "Internal Boundary Layer Structure Observed by dualDoppler lidar." 5th Symposium on Lidar Atmospheric Applications, Seattle, WA, 23-27 January 2011. American Meteorological Society, Boston.

Pearson, G, F Davies, and C Collier. 2009. "An Analysis of the Performance of the UFAM Puylsed Doppler Lidar for Observing the Boundary Layer." Journal of Atmospheric and Oceanic Technology 26(2): 240-250.

Rye BJ and RM Hardesty. 1993. "Discrete Spectral Peak Estimation in Incoherent Backscatter Heterodyne Lidar. II: Correlogram Accumulation.” IEEE Transactions on Geoscience and Remote Sensing 31(1): 28-35.

Rye BJ and RM Hardesty. 1997. "Estimate Optimization Parameters for Incoherent Backscatter Heterodyne Lidar." Applied Optics 36(36): 9426-9436.

Reisner JM and PK Smolarkiewicz. 1994. "Thermally Forced Low Froude Number Flow Past ThreeDimensional Obstacles.” Journal of Atmospheric Sciences 51(1): 117-133.

Stensrud DJ. 1996. "Importance of Low-Level Jets to Climate: A Review." Journal of Climate 9(8): $1698-1711$.

Stull RB. 1988. An Introduction to Boundary Layer Meteorology. Kluwer Academic Publishers, 596600.

Thorpe AJ and TH Guymer. 1977. "The Nocturnal Jet." Quarterly Journal of the Royal Meteorological Society 103(438): 633-653.

Warner T, P Benda, S Swerdlin, J Knievel, E Argenta, B Aronian, B Balsley, J Bowers, R Carter, P Clark, K Clawson, J Copeland, A Crook, R Frehlich, M Jensen, Y Liu, S Mayor, Y Meillier, B Morley, R 
Sharman, S Spuler, D Storwold, J Sun, J Weil, M Xu, A Yates, and Y Zhang. 2007. "The Pentagon Shield Field Program, Toward Critical Infrastructure Protection." Bulletin of the American Meteorological Society $88,167-176$.

Whiteman CD, X Bian and S Zhong. 1997. "Low-Level Jet Climatology from Enhanced Rawinsonde Observations at a Site in the Southern Great Plains." Journal of Applied Meteorology 36: 1363-1376. 


\section{Appendix B \\ Data Availability Plots}

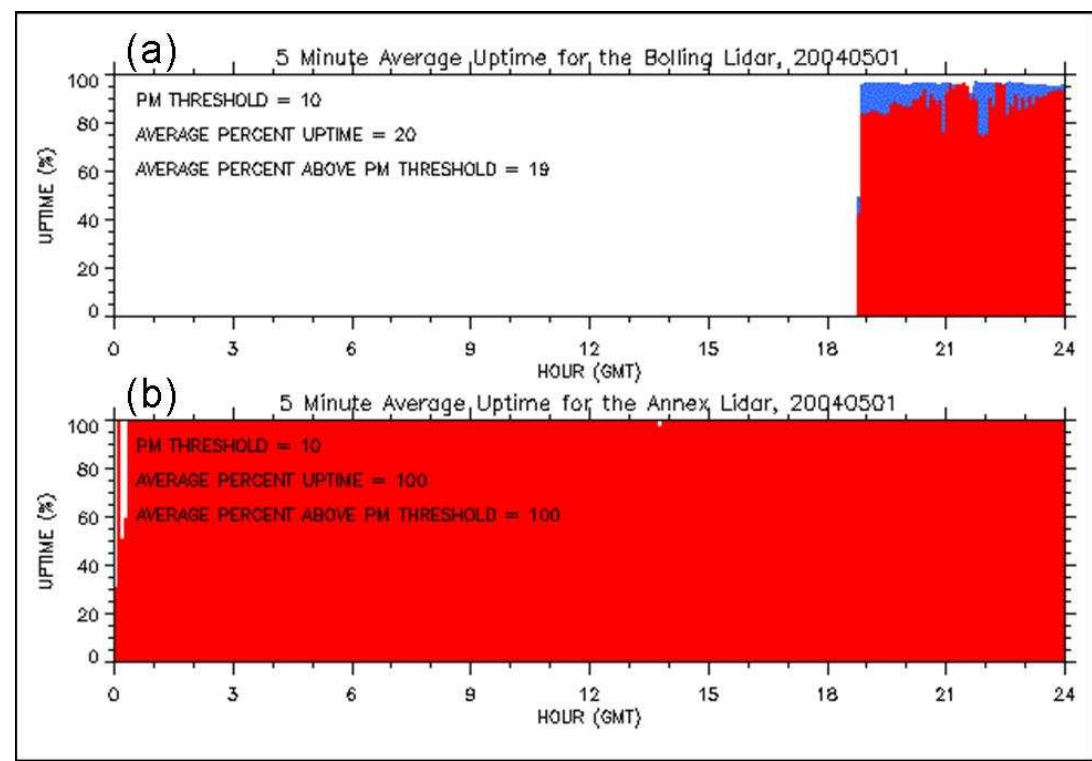

Figure B1. Time series of data availability for (a) the Bolling and (b) the Annex lidars during 1 May 2004. Blue indicates periods when the lidar was operating, while the red indicates the fraction of time that the pulse monitor signal exceeded 10.

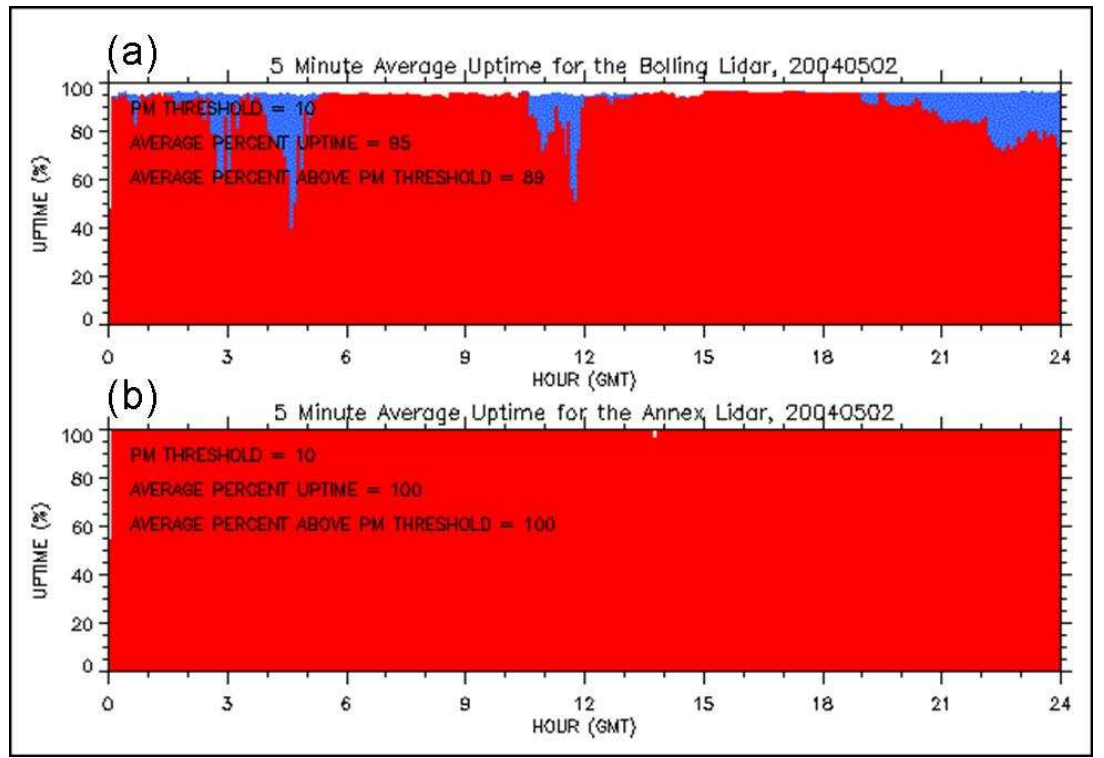

Figure B2. This is the same as Figure B1 except 2 May 2004. 


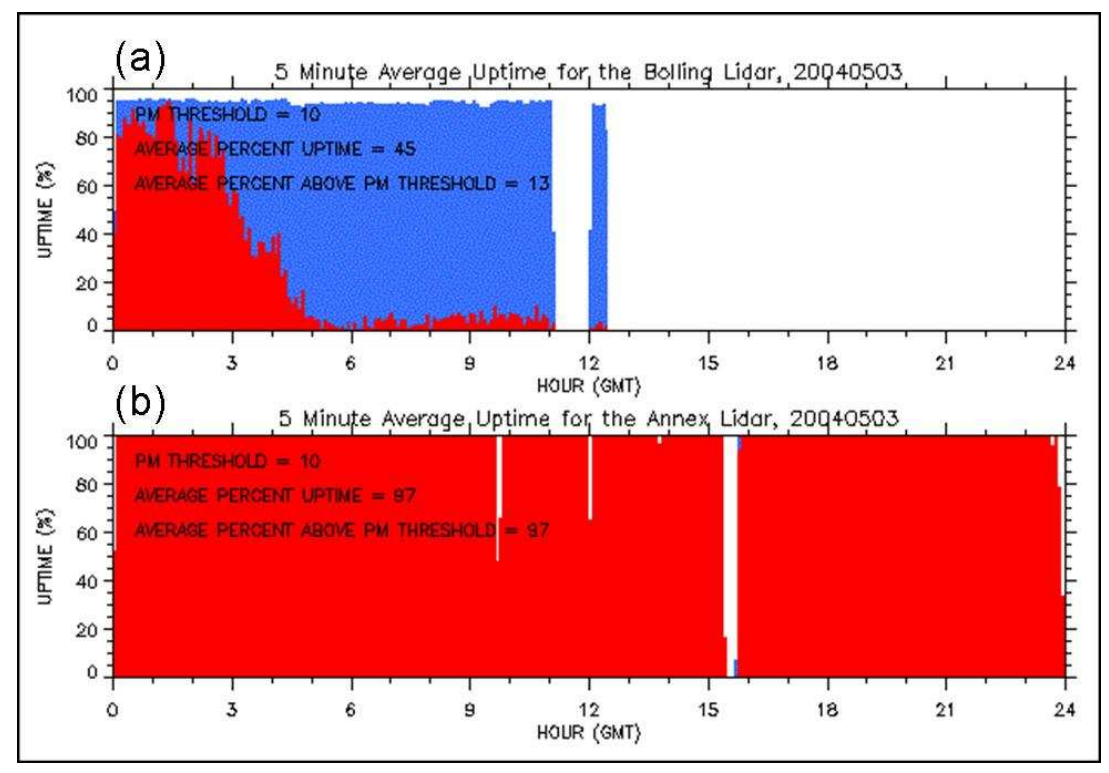

Figure B3. This is the same as Figure B1 except 3 May 2004.

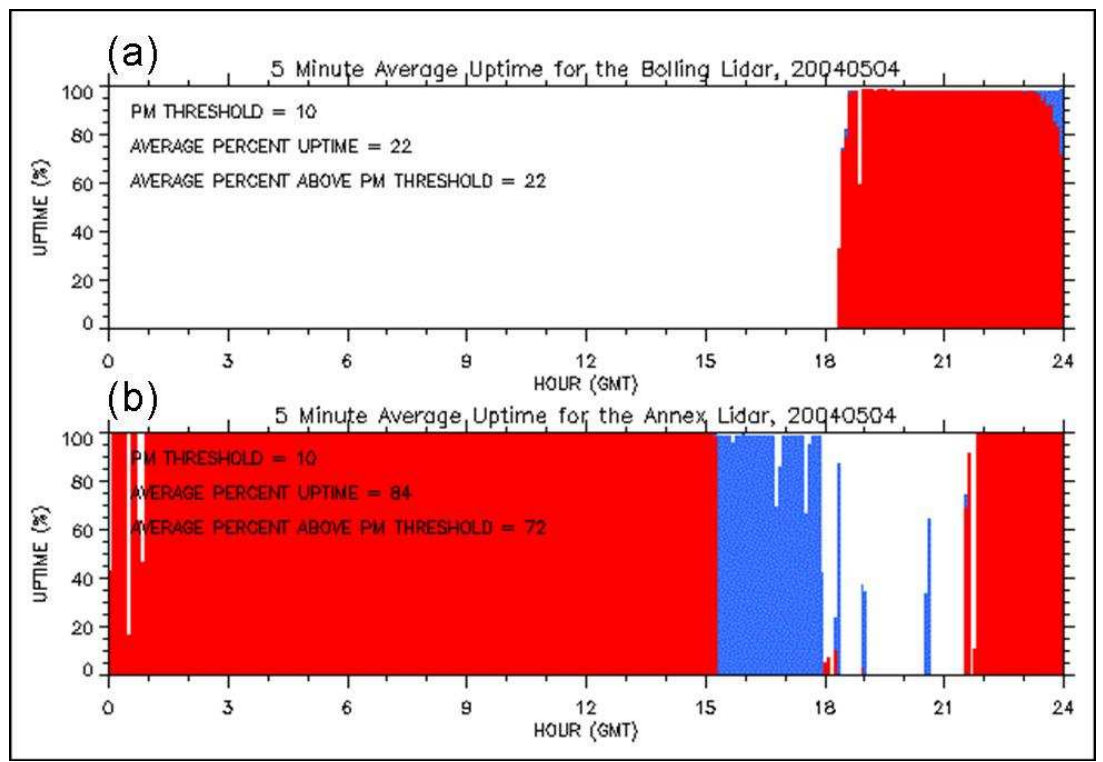

Figure B4. This is the same as Figure B1 except 4 May 2004. 


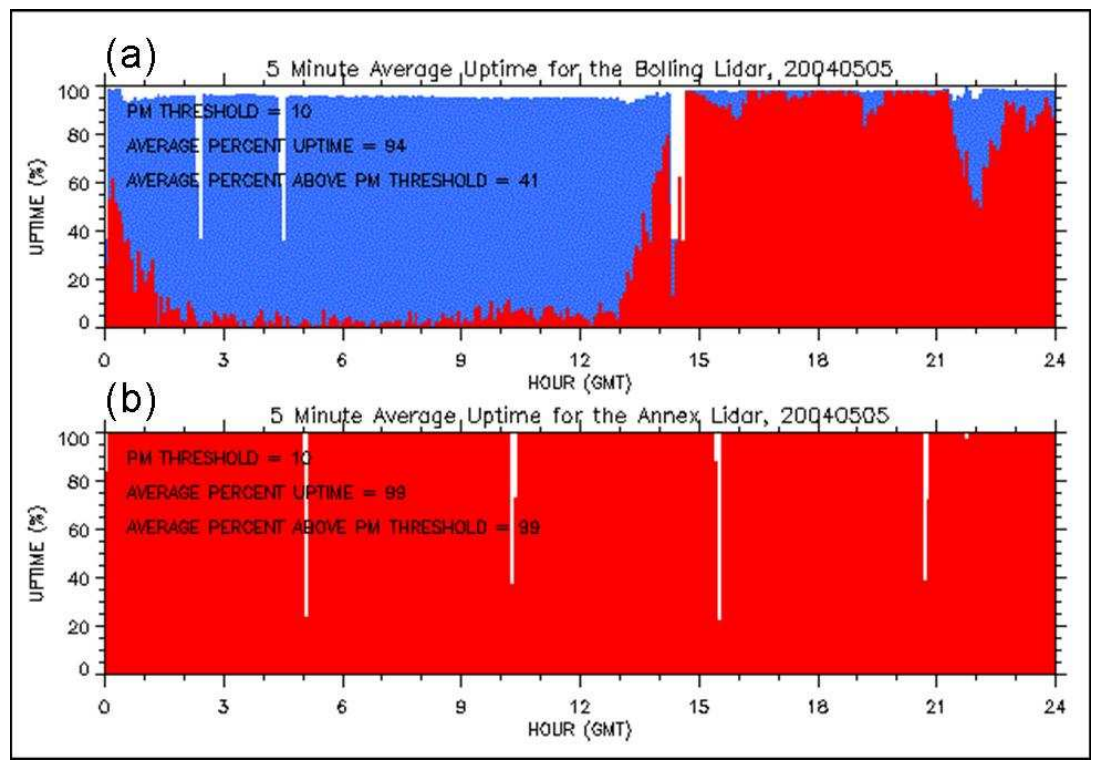

Figure B5. This is the same as Figure B1 except 5 May 2004.

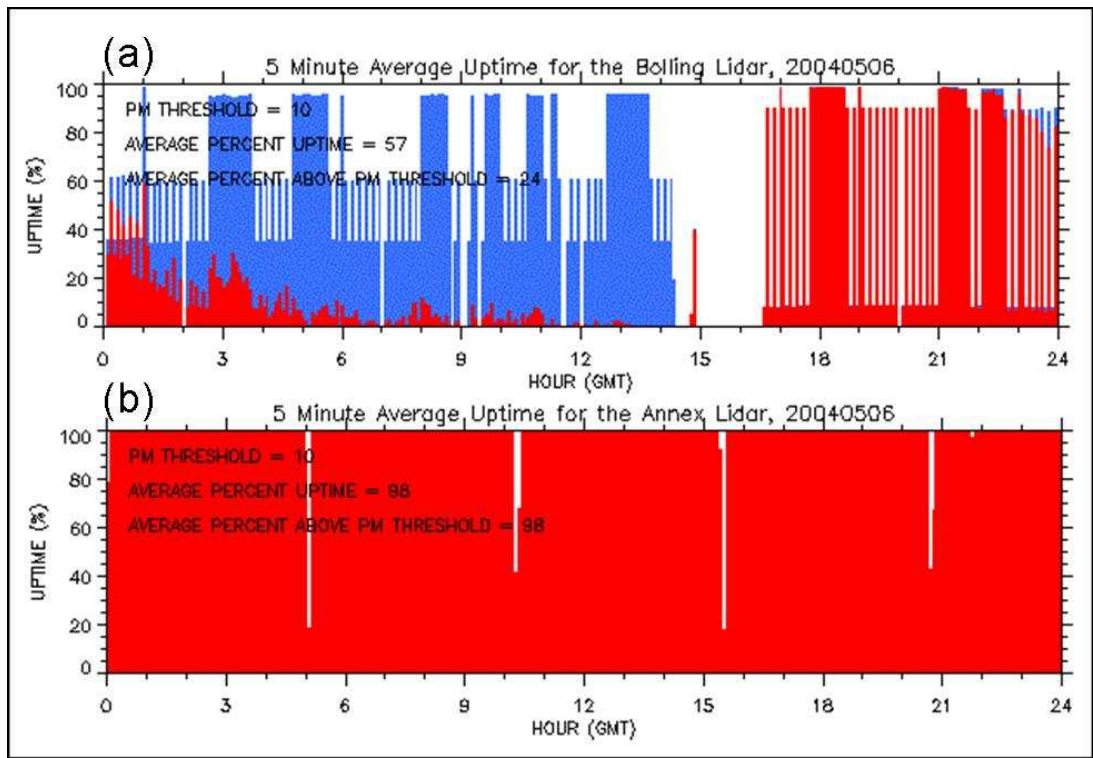

Figure B6. This is the same as Figure B1 except 6 May 2004. 


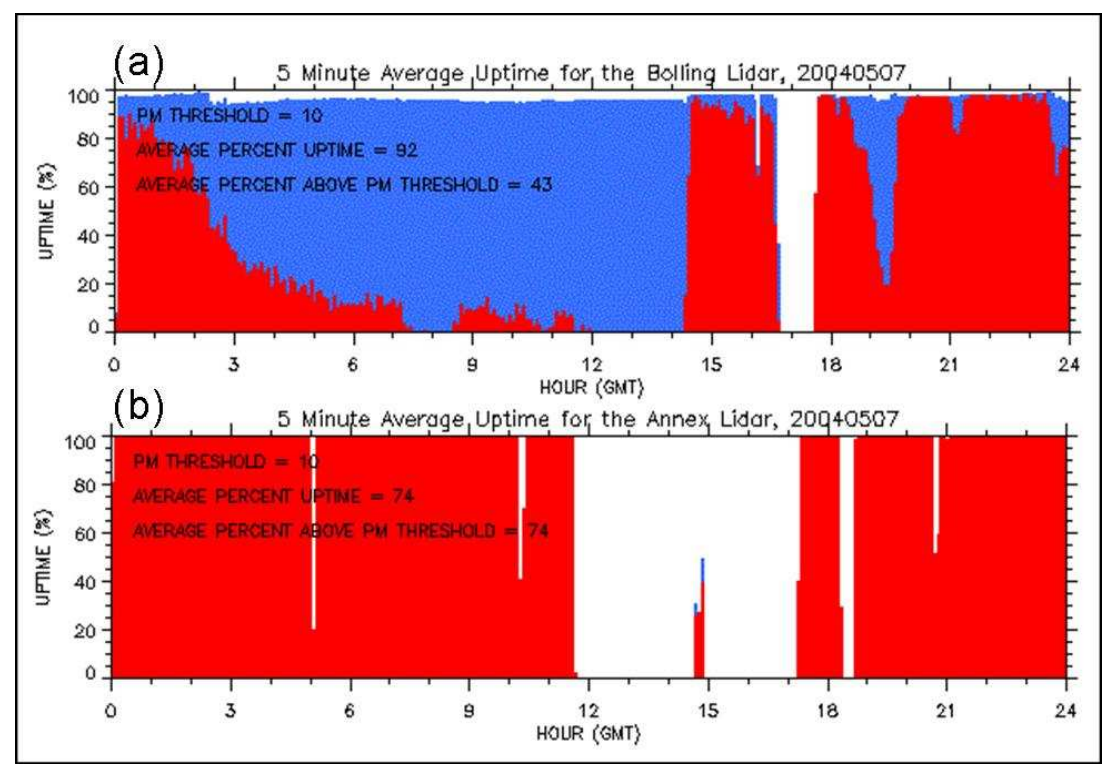

Figure B7. This is the same as Figure B1 except 7 May 2004.

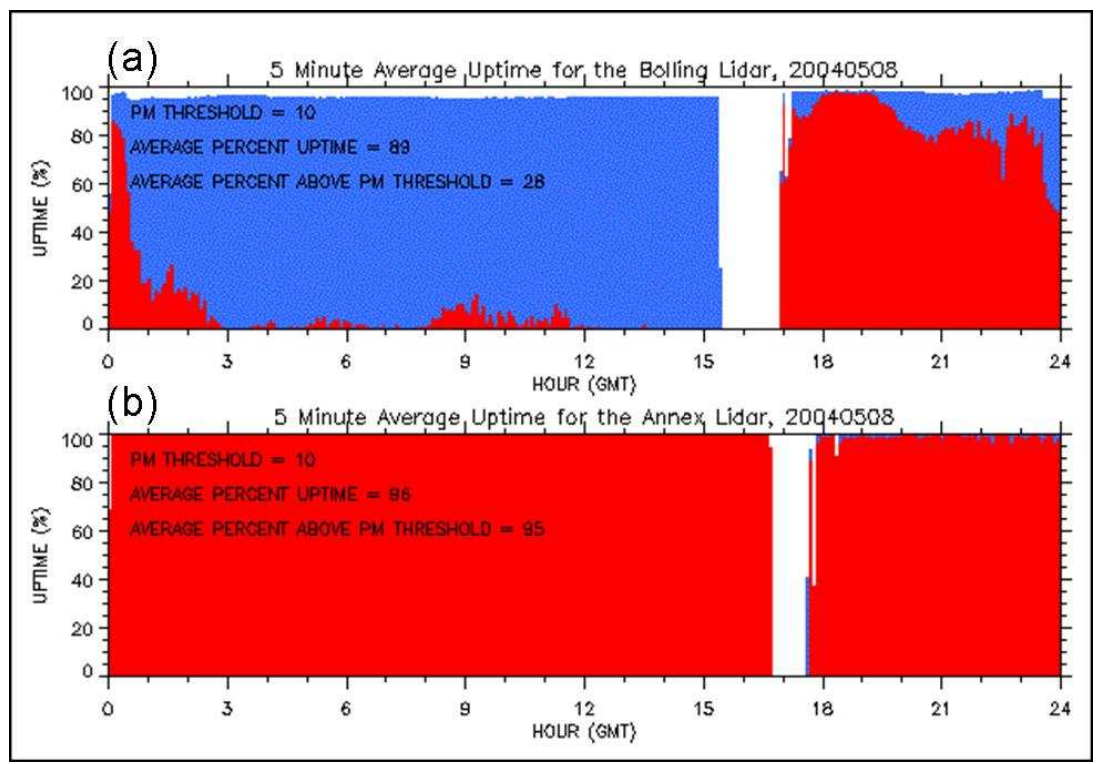

Figure B8. This is the same as Figure B1 except 8 May 2004. 


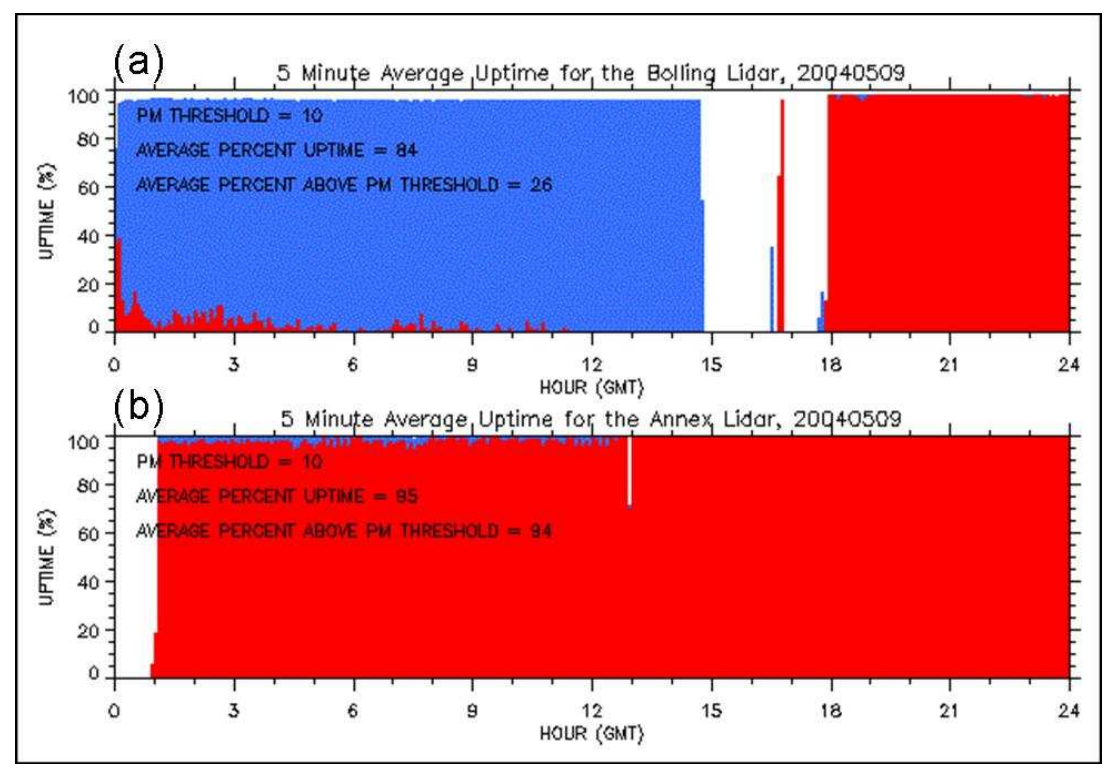

Figure B9. This is the same as Figure B1 except 9 May 2004.

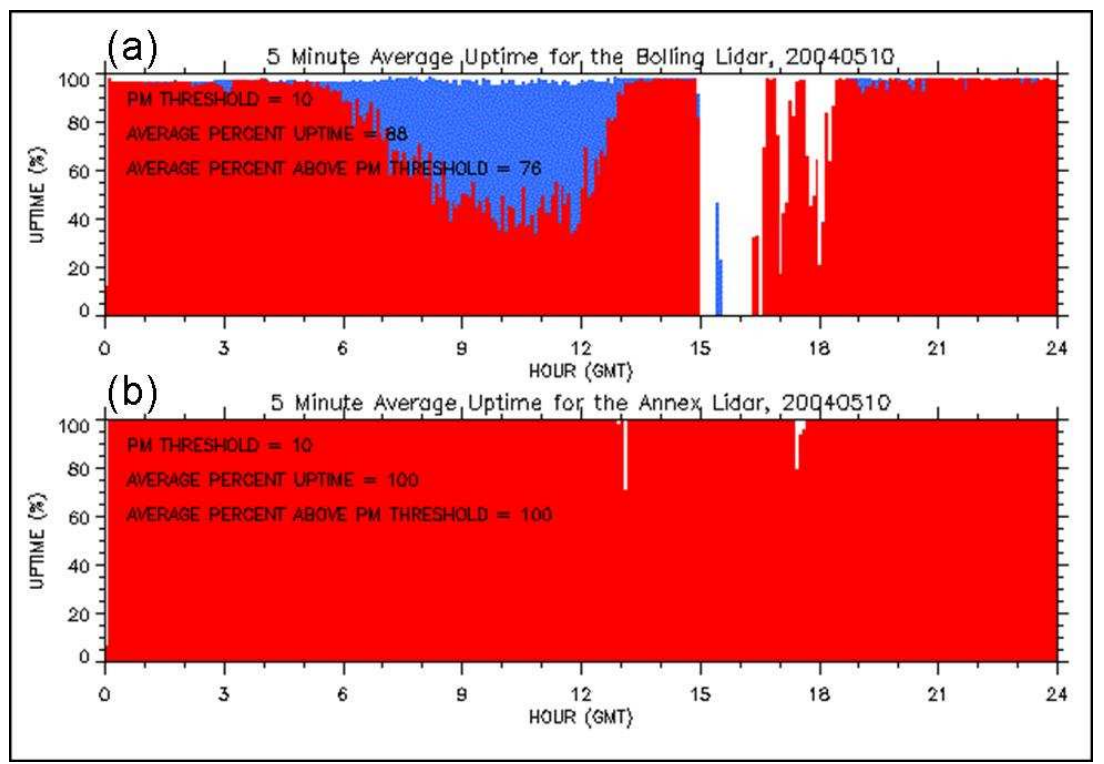

Figure B10. This is the same as Figure B1 except 10 May 2004. 


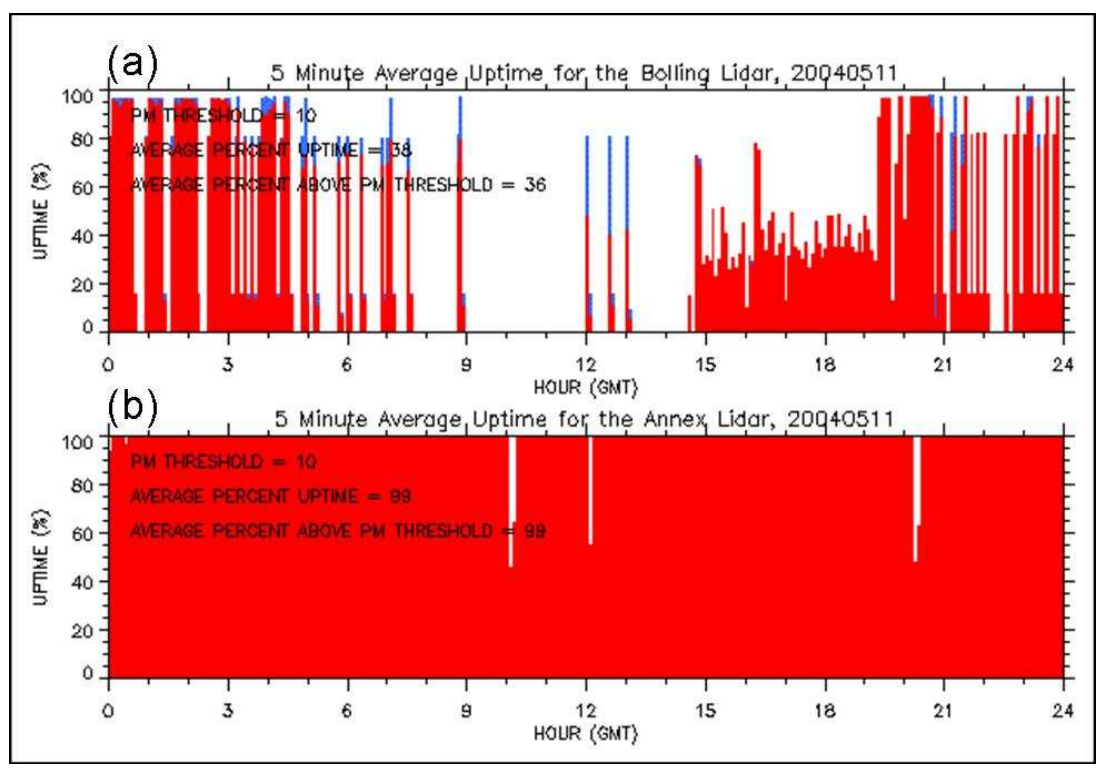

Figure B11. This is the same as Figure B1 except 11 May 2004.

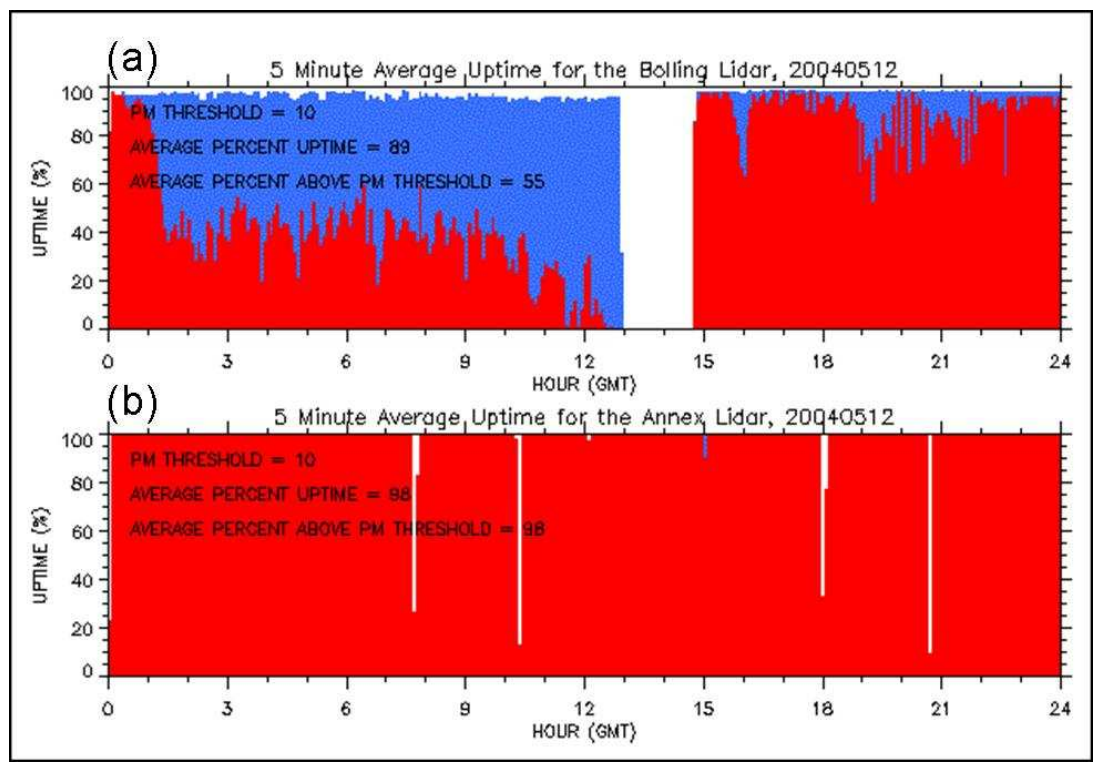

Figure B12. This is the same as Figure B1 except 12 May 2004. 


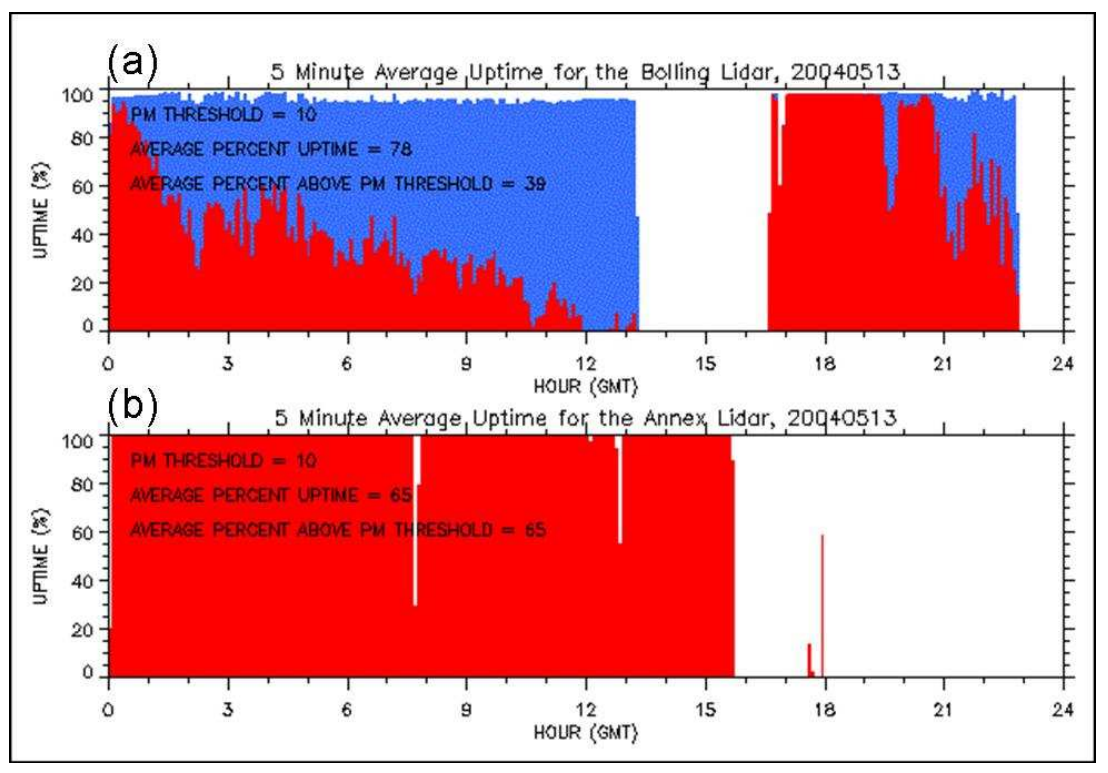

Figure B13. This is the same as Figure B1 except 13 May 2004. 


\section{Distribution}

No. of

Copies

1 Gorden Videen

Army Research Laboratory RDRL-CIE-S

2800 Powder Mill Road

Adelphi MD 20783 USA
No. of

\section{Copies}

1 Local Distribution

Pacific Northwest National Laboratory

Larry Berg

(PDF) 




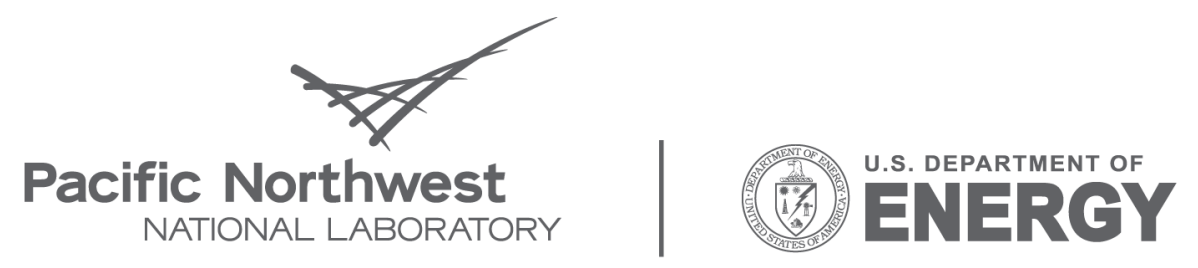

Proudly Operated by Battelle Since 1965

902 Battelle Boulevard

P.O. Box 999

Richland, WA 99352

1-888-375-PNNL (7665)

www.pnl.gov 